\title{
Regulation of STAT3 and its role in cardioprotection by conditioning: focus on non-genomic roles targeting mitochondrial function
}

\author{
Stefano Comità ${ }^{1}$ Saveria Femmino ${ }^{2} \cdot$ Cecilia Thairi $^{1} \cdot$ Giuseppe Alloatti $^{3} \cdot$ Kerstin Boengler $^{4} \cdot$ Pasquale Pagliaro $^{1}$ (i) . \\ Claudia Penna ${ }^{1}$
}

Received: 17 May 2021 / Revised: 23 September 2021 / Accepted: 27 September 2021 / Published online: 12 October 2021

(C) The Author(s) 2021

\begin{abstract}
Ischemia-reperfusion injury (IRI) is one of the biggest challenges for cardiovascular researchers given the huge death toll caused by myocardial ischemic disease. Cardioprotective conditioning strategies, namely pre- and post-conditioning maneuvers, represent the most important strategies for stimulating pro-survival pathways essential to preserve cardiac health. Conditioning maneuvers have proved to be fundamental for the knowledge of the molecular basis of both IRI and cardioprotection. Among this evidence, the importance of signal transducer and activator of transcription 3 (STAT3) emerged. STAT3 is not only a transcription factor but also exhibits non-genomic pro-survival functions preserving mitochondrial function from IRI. Indeed, STAT3 is emerging as an influencer of mitochondrial function to explain the cardioprotection phenomena. Studying cardioprotection, STAT3 proved to be crucial as an element of the survivor activating factor enhancement (SAFE) pathway, which converges on mitochondria and influences their function by cross-talking with other cardioprotective pathways. Clearly there are still some functional properties of STAT3 to be discovered. Therefore, in this review, we highlight the evidence that places STAT3 as a promoter of the metabolic network. In particular, we focus on the possible interactions of STAT3 with processes aimed at maintaining mitochondrial functions, including the regulation of the electron transport chain, the production of reactive oxygen species, the homeostasis of $\mathrm{Ca}^{2+}$ and the inhibition of opening of mitochondrial permeability transition pore. Then we consider the role of STAT3 and the parallels between STA3/STAT5 in cardioprotection by conditioning, giving emphasis to the human heart and confounders.
\end{abstract}

Keywords $\mathrm{Ca}^{2+}$ regulation $\cdot$ Ischemia reperfusion injury $\cdot$ Mitochondrial permeability transition pore $\cdot$ Reactive oxygen species $\cdot$ RISK pathway $\cdot$ SAFE pathway $\cdot$ STAT3 $\cdot$ STAT5

Stefano Comità, Saveria Femmino and Cecilia Thairi share first authorship.

Pasquale Pagliaro

pasquale.pagliaro@unito.it

Claudia Penna

claudia.penna@unito.it

1 Department of Clinical and Biological Sciences, University of Turin, Regione Gonzole 10, Orbassano, 10043 Torino, TO, Italy

2 Department of Medical Sciences, University of Turin, Torino, Italy

3 Uni-Astiss, Polo Universitario Rita Levi Montalcini, Asti, Italy

4 Institute of Physiology, University of Giessen, Giessen, Germany

\section{Introduction}

Global health is constantly threatened by cardiovascular diseases (CVDs) and every year $31 \%$ of worldwide deaths are caused by fatal CVDs. According to the World Health Organization, CVDs caused 17.9 million deaths in 2016. Among these, $85 \%$ are attributed to ischemic heart disease or stroke [186].

Over the past twenty to thirty years, mortality from ischemic heart disease has significantly decreased. However, currently available therapies improve symptoms and slow pathological heart remodeling but fail to further reduce CVD mortality [178]. A complete understanding of the molecular targets and mechanisms underlying heart disease is certainly the key to developing new and effective therapeutic strategies. 
Coronary reperfusion is currently the "gold standard" for saving the lives of patients with acute myocardial infarction (MI). Reperfusion is mandatory to avoid fatal damage to the ischemic myocardium. However, the reperfusion itself contributes to exacerbating the damage and the extent of the infarct size (IS). In this regard, cardiovascular research over the years has investigated how to limit ischemia-reperfusion injury (IRI), leading to the development of cardioprotective maneuvers, which allowed researchers to analyze and understand the molecular aspects of IRI [77].

Already in 1972 Braunwald and collaborators suggested that the infarct area was not only a function of the duration of ischemia, the area at risk and collateral flow, but could also be reduced with cardioprotective interventions [144]. However, only in 1986 Murry et al. [153] demonstrated in an animal model that a few minutes of coronary occlusion interspersed with a few minutes of reperfusion reduced the area of myocardial infarction caused by a subsequent period of prolonged lethal ischemia/reperfusion (IR). This was the discovery of ischemic preconditioning (IPreC) as a powerful endogenous cardioprotective phenomenon. However, only 4 years later another laboratory confirmed this original observation [130]. Since that time, the IS-limiting effects of IPreC have been demonstrated in all species tested, including humans and have also been shown to be effective in the multicenter network of experimental research centers that made up the Consortium for preclinicAl assESsment of cARdioprotective therapies (CAESAR) [94]. It was then demonstrated that the preconditioned state resulted from protective signal transduction [226]. It was discovered that a short coronary occlusion releases ligands (e.g., adenosine, bradykinin, opioids, platelet activating factor and/or sphingosine) which acting on their receptors trigger protective cascades that converge on protein kinase $\mathrm{C}$ (PKC) $[138,166]$ and on mitochondria [137]. The production of reactive oxygen species (ROS) with a trigger role for cardioprotection also plays an important role in this mechanism [212]. The importance of mitochondria in these phenomena is certain, as much of the cell death in the heart is due to the formation of mitochondrial permeability transition pores (mPTPs) in the first minutes of reperfusion, which is prevented by conditioning procedures $[75,78]$.

The cardioprotective pathways are not yet fully understood, but in the early 2000s, Yellon's group [72, 182] proposed the reperfusion injury salvage kinase (RISK) pathway, which includes pro-survival kinases that must be activated at the time of reperfusion to protect against IRI (Fig. 1). Then, studies have shown that it is possible to protect the heart with short intermittent phases of ischemia applied at the beginning of reperfusion, ischemic postconditioning (IPostC) [215, 248], as well as by ischemia in tissues and organs remote to the heart, remote ischemic conditioning (RIC) [171]. Indeed, these conditioning maneuvers trigger via multiple mechanisms various cardioprotective pathways besides the RISK, including the NO/PKG (nitric oxide/ cyclic guanosine monophosphate (cGMP)-dependent protein kinase G; Fig. 1), and the so-called survivor activating factor enhancement (SAFE) pathways, which can cross-talk (Figs. 1 and 2) [71, 197, 209]. The SAFE pathway was proposed in 2009 by Lecour et al. [113], it considers a central role for the signal transducer and activator of transcription 3 (STAT3) and will be described in more detail throughout this review article.

The importance of the RISK and/or SAFE pathway has been demonstrated in all forms of ischemic conditioning (IPreC, IPostC and RIC) as well as in that obtained with substances administered before or after infarcting ischemia (pharmacological conditioning) [69, 238]. The mechanisms induced by pharmacological conditioning are similar to IPreC and IPostC, with the difference that pharmacological conditioning could be applied in a less invasive way. Indeed, in animal and clinical studies, many substances have shown to induce protection against myocardial IR, including volatile anesthetics, opioids, some anti-diabetic drugs, statins but also endogenous substances and hormones, such as adenosine, leptin, insulin and ghrelin [71, 114, 115, 168]. In addition, hypothermic conditioning by mild hypothermia $\left(32-35^{\circ} \mathrm{C}\right)$ has been described in the contest of myocardial protection and STAT3 in animal and in clinical studies [88, $161,163]$. It is now clear that targeting intra-cardiomyocytes pathways together a multitarget approach is necessary for a successful cardioprotective strategy (EU-CARDIOPROTECTION COST Action CA16225) [39].

Of note, in preconditioning obtained with interventions/ agents, the cardioprotection occurs in two phases, in which STAT3 has been seen to play a pivotal role, as member of the SAFE pathway. The first phase is called classical or early preconditioning and lasts $2-3 \mathrm{~h}$. The second phase is called second window of protection (SWOP) or delayed or late preconditioning. It starts about $12 \mathrm{~h}$ after the IPreC maneuvers and lasts 48-72 h [73].

Although, STAT3 is involved as a transcription factor inducing the upregulation of antioxidant, antiapoptotic and pro-angiogenic genes in SWOP [22, 251], it has been recently observed in cardiac mitochondria in the maintenance of electron transport chain (ETC) activity and in the prevention of opening of mPTPs $[225,236]$. In addition, the mitochondrial activity of STAT3 is emerging as an important factor and may represent the needle of the balance in mechanisms that confer cardioprotection. Notwithstanding that some studies reported the role of STAT3 in cardiac conditioning, others evidenced the important involvement of STAT5 for the translation of cardioprotection [e.g., 56, 80].

Therefore, in this review we first briefly describe the structure of STAT3 and the principal STAT3 post-translational modifications. Then we focus on the role of STAT3 


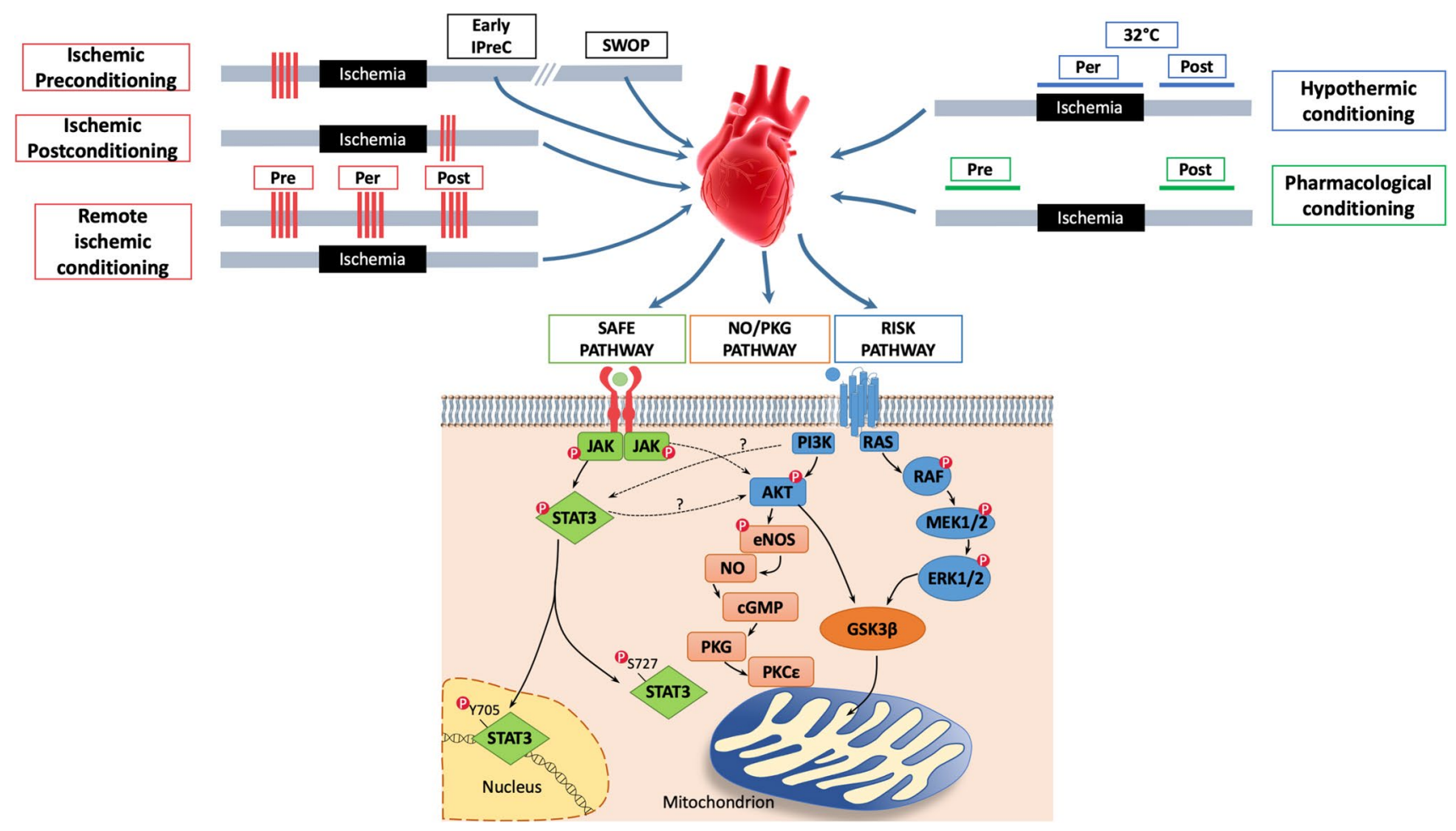

Fig. 1 Cardiac conditioning can be induced by brief periods of ischemia (red lines), that is ischemic preconditioning (IPreC), postconditioning (IPostC) and remote conditioning (RIC), as well as by hypothermic or pharmacological interventions. Pre-, Per- and Postconditioning are able to protect the heart $v s$ IRI, by triggering three main transduction pathways, SAFE, RISK and NO/PKG pathways; these pathways can cross-talk and result in the activation of antiapoptotic stimuli and the preservation of mitochondrial function. Akt Protein kinase B, $c G M P$ cyclic Guanosine Monophosphate, eNOS

within mitochondria highlighting the evidence that places STAT3 as a promoter of the metabolic network. In particular, we focus on the possible interactions of STAT3 with the ETC, the production of ROS, the $\mathrm{Ca}^{2+}$ homeostasis, the mitochondria quality control and the inhibition of mPTPs opening. We also provide a critical evaluation of pathophysiological roles of STAT3 and the parallels between STA3/ STAT5 in the context of cardiac IRI. Finally, we discuss the role of STAT3 in the cardioprotection by ischemic and pharmacological/hypothermic conditioning and the effects of common risk factors and confounders on STAT3-mediated cardioprotection in cells, in animal models and in the human heart.

\section{STAT3 overview}

To begin, we briefly consider STAT3 structure, evolutionary conservation of stat genes, their regulation and the subcellular STAT3 localization. For a more detailed description the readers are kindly redirected to recent reviews $[10,60,223]$. endothelial Nitric Oxide Synthase, ERK1/2 Extracellular Receptor Kinase $1 / 2$, GSK3 $\beta$ Glycogen Synthase Kinase-3 $\beta$, IPreC Ischemic PreConditioning, JAK Janus Kinase, MAPK Mitogen-Activated Protein Kinase, MEK MAPK/ERK Kinase, $N O$ Nitric Oxide, PI3K PhosphatidylInositol-4,5-bisphosphate 3-Kinase, $P K C \varepsilon$ Protein Kinase $\mathrm{C}$ $\varepsilon$ subtype, $P K G$ Protein Kinase G, $R A F$ serine/threonine kinase, $R A S$ rat Sarcoma Virus, RISK Reperfusion Injury Salvage Kinase, SAFE Survivor Activating Factor Enhancement, STAT3 Signal Transducer and Activator of Transcription 3

\section{Structure of STAT3}

STAT3 together with STAT 1-2-4, STAT5a-b, and STAT6 are members of the STAT family. These proteins exhibit different functions while having an almost similar structure. This family of signal molecules appeared early in evolution and differentiated during the evolution of animal species. During animal development, the STAT signaling pathway regulates cell fate decisions. Comparative genomics displayed multiple duplications of the stat gene that occurred throughout the evolutionary history of metazoans. Many of these STAT duplications evolved into new genes through rapid sequence differentiation and the acquisition of new functions. It appears that the regulatory networks of stat genes, which include stat1, 4, 5 and stat6, appeared early in vertebrate evolution. Among the STAT genes, the gene encoding STAT3 is the only one that is essential for the early development of vertebrate embryos and results in embryonic lethality if it is completely deleted [207]. In mammals, the two stat 5 genes likely arose from a duplication event in early Eutherian evolution, a period from about 310 to 130 


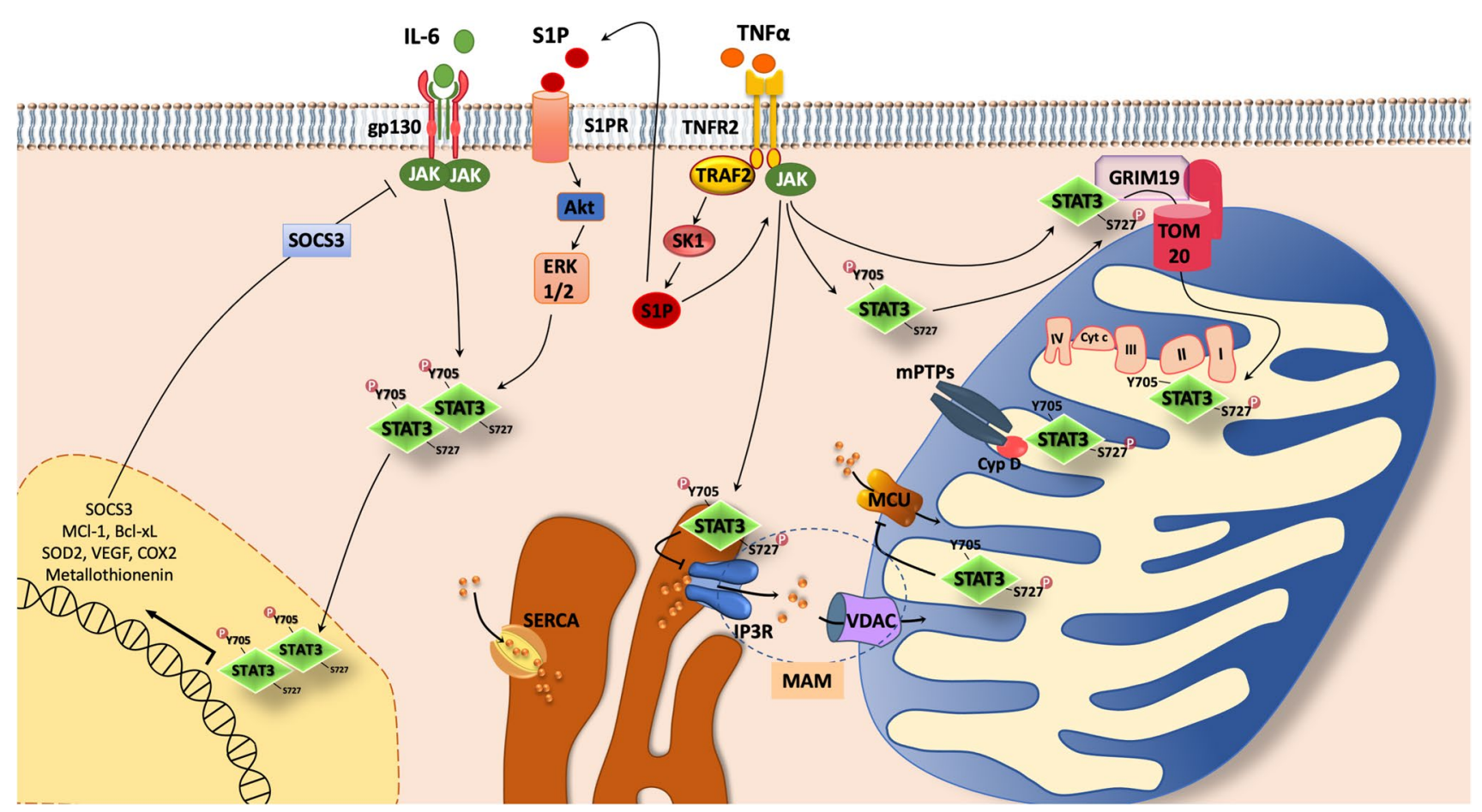

Fig. 2 STAT3 canonical and non-canonical pathways. In SAFE pathway JAK/STAT3 can be activated upon activation of receptors including gp130, TNFR2, S1PR. Other molecules (not represented in figure) may activate SAFE pathway, including HDL, Melatonin, Erythropoietin, Insulin and Leptin. Upon phosphorylation at Y705 and dimerization, STAT3 dimer travels to the nucleus, where it regulates gene transcription. The phosphorylation at S727 may allow STAT3 to interact with GRIM19 and TOM20 to enter the mitochondria. STAT3 has been shown to interact with multiple mitochondrial proteins, such as $\mathrm{MCU}$, promoting mitochondrial $\mathrm{Ca}^{2+}$ entry, complex I and II of the ETC, increasing ATP level and decreasing ROS production. STAT3 interacting with CypD prevents the opening of mPTPs. STAT3 has been detected also in the MAM fraction, where it is able to promote IPR3 degradation and prevent cytosolic $\mathrm{Ca}^{2+}$ accumulation. Akt Protein kinase B, ATP adenosine triphosphate, $B c l$ $x L$ B-cell lymphoma-extra large, $C O X 2$ Cytochrome c oxidase subunit 2, CypD Cyclophilin D, Cyt C Cytochrome C, ER Endoplasmic

million years ago when the avian-mammal divergence and the separation of marsupials from other mammals occurred $[60,223]$. These comparative analyzes indicate that genomewide duplications and gene duplications for unbalanced chromosomal crossings were probably the main mechanisms underlying the evolution of STATs [223]. The selective persistence of the basic domains required for phospho-tyrosine signaling, as well as the Src homology-2 (SH2) domain and a site for protein tyrosine phosphorylation, suggest the importance of these modules in all multicellular organisms. It is, therefore, of particular interest that the different proteins of the STAT family have acquired additional functions, apparently independent of phospho-tyrosine, without losing their participation in the basic signaling mode $[61,121$, 225].
Reticulum, ERK1/2 Extracellular Receptor Kinase 1/2, ETC Electron Transport Chain, gp130 glycoprotein 130, GRIM19 Gene associated with Retinoid Interferon-induced cell Mortality 19, $H D L$ High Density Lipoprotein; IP3R, Inositol 1,4,5-trisphosphate Receptors, JAK Janus Kinase, MAM Mitochondrial-Associated ER Membrane, $\mathrm{MCl}-1$ Myeloid cell leukemia 1, MCU Mitochondrial Calcium Uniporter, mPTP mitochondrial Permeability Transition Pore, ROS Reactive oxygen species, S1P Sphingosine-1-Phosphate, S1PR Sphingosine1-Phosphate Receptors, SAFE Survivor Activating Factor Enhancement, SERCA Sarco-Endoplasmic Reticulum Calcium ATPase, SK1 Sphingosine Kinase 1, SOCS3 Suppressor of Cytokine Signaling 3; SOD2 Superoxide dismutase 2, STAT3 Signal Transducer and Activator of Transcription 3, TNFR2 Tumor Necrosis Factor Receptor 2; TOM20Translocase of the outer membrane 20, TRAF2 TNF-Receptor-Associated-Factor 2, VDAC Voltage-Dependent Anion Channels, $V E G F$ Vascular endothelial growth factor

Members of the STAT family interact with janus kinase (JAK) proteins, including JAK1, JAK2, JAK3 and tyrosine kinase 2 (TYK2) [12]. For details on this interaction, the reader is redirected to a previous review [129].

The human STAT3 protein $(89 \mathrm{kDa})$, encoded by the stat 3 gene, is constituted by 770 amino acids that are organized in 6 different domains [111] (Fig. 3). STAT3 contains an $\mathrm{N}$-terminal oligomerization domain (OLG), whose role is still unclear; it does not seem to be involved in the formation of phosphorylated STAT3 homodimers nor in the interaction with DNA, but is suggested to play a role in non-canonical STAT3 signaling and in the formation of unphosphorylated STAT3 dimers [44]. Close to the OLG domain is the coiled-coil dimerization domain, which is involved in the interaction of STAT3 with regulators and other transcription 


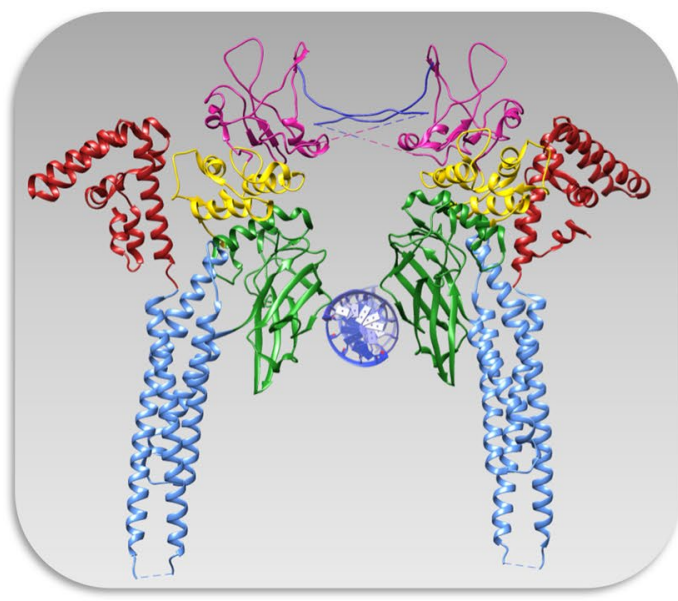

NTD
CCD
DBD
LD
SH2
TAD

Fig. 3 Structural representation of STAT3 dimer bound to a DNA molecule (molecular graphic performed with UCSF Chimera) and schemes of STAT3 $\alpha$ and STAT3 $\beta$ domains. Red asterisks represent
Y705 and S727 phosphorylation sites. DNA Deoxyribonucleic acid, STAT3 Signal Transducer and Activator of Transcription 3, UCSF University of California, San Francisco factors. STAT3 comprises also a DNA binding domain (DBD) that is able to interact with the interferon $\gamma$-activated sequence (GAS) in the promoter of specific genes; the interaction with the DNA is mediated by four loops of STAT3, three loops belong to the DNA binding domain and one to the linker domain [13]. The linker domain also cooperates with the $\mathrm{SH} 2$ domain in the recognition of YXXQ sites. The $\mathrm{SH} 2$ domains recognize phosphorylated tyrosine residues of activated STAT3, allowing the formation of STAT3 homodimers that are essential in the canonical STAT3 signaling. The SH2 domains mediate the recognition of other phosphorylated tyrosine residues, for example on glycoprotein 130 receptor (gp130) [222]. Although the SH2 domain is highly conserved in the STAT family, it was possible to design specific inhibitors of STAT3 targeting the $\mathrm{SH} 2$ domain, such as Stattic or S3I-201 [41].

At the C-terminus, the transcription activation domain (TAD) can be detected with two phosphorylation sites, Tyrosine 705 (Y705) and Serine 727 (S727). The STAT3 phosphorylation at these two sites will be recognized by a specific pocket in the $\mathrm{SH} 2$ domain of the other STAT3 monomer; therefore, TAD domain participates in the stability of the homodimer and to activation of STAT3 signaling. For the recognition of Y705 and S727, the SH2 domain of STAT3 requires the presence of arginine, R609 that is highly conserved in all SH2 domains [184]. There are two main isoforms of STAT3 ( $\alpha$ and $\beta$ ), which differ in the length of the C-terminus: the most abundant STAT3 $\alpha$ comprises 770 amino acids and the less frequent STAT3 $\beta$, which lacks 48 amino acids of the TAD, including the $\mathrm{S} 727$ phosphorylation site (Fig. 3) [184].

STAT3 canonical functions are primarily described as translocation from cytoplasm to the nucleus, where it acts as a transcription factor. However, STAT3 acts in non-canonical ways outside from the nucleus, by regulating the functions of mitochondria, endoplasmic reticulum (ER) and lysosomes. Yet, co-localization of cytoplasmic STAT3 with a microtubule-destabilizing protein stathmin favors microtubule polymerization and cell movement [158].

Effects of STAT3 on mitochondrial function are described below (see "Effects of STAT3 on mitochondrial function"). Here, we briefly describe the role in lysosomes and ER. STAT3 associates with lysosomes, spherical vesicles whose lumen's acidic $\mathrm{pH}(\sim 4.5-5.0)$ is optimal for the enzymes involved in hydrolysis of different biomolecules. In lysosomes, STAT3 stimulates V-ATPase activity and contributes to the preservation of the acidic lysosomal lumen and the alkaline cytosol [135]. The ER is the principal $\mathrm{Ca}^{2+}$ storage compartment and its close contact with mitochondria membrane determines mitochondrial $\mathrm{Ca}^{2+}$ responses in many cell types [176]. STAT3 phosphorylation at Y705 and S727 residues (see below "Phosphorylation at Y705 and S727") are not required for either ER localization or Inositol 1,4,5-trisphosphate Receptor (IP3R) type 3 (IP3R3) interaction. However, the phosphorylation on S727 may play an important regulatory role, as murine embryonic fibroblast cells expressing a STAT3 mutant on $\mathrm{S} 727$ showed excess $\mathrm{Ca}^{2+}$ release and apoptotic cell death after treatment with $\mathrm{H}_{2} \mathrm{O}_{2}$ or the intracellular ROS generator menadione, which induce cell death by apoptosis. These effects were not observed in wild type cells. Furthermore, ER STAT3 acts by promoting the proteasomal degradation of IP3R3, probably through the ubiquitin E3 ligase FBXL2 in mammalians [9, 103]. These observations are consistent with the fact that some breast cancers show an inverse correlation between phospo-STAT3 and IP3R3 protein levels [9]. 


\section{Post-translational modifications of STAT3: focus on the SAFE pathway}

STAT3 post-translational regulations include phosphorylations and alternative post-translational modifications.

Apart from the phosphorylation of Y705 and/or S727 residues, STAT3 is reported to undergo alternative posttranslational modifications, such as K685 acetylation, or C259 nitrosylation, and other modifications in non-canonical pathways. Here, for space constraint, we choose to consider mainly Y705 and S727 phosphorylation, which are pivotal in the SAFE pathway. All post-translational modifications are described and summarized in Table 1; for further information about STAT3 post-translational modifications the reader is redirected to previous reviews $[66,251]$.

\section{Phosphorylation at Y705 and S727}

It seems that, while the Y705 phosphorylation of STAT3 is necessary for homodimerization and translocation in the nucleus, S727 phosphorylation is necessary for its translocation into the mitochondria [78, 79, 225]. Data suggest that a dynamic balance exists between the phosphorylation of Y705 and S727, which is achieved through a possible inhibitory effect of phosphorylated S727 on phosphorylated Y705 [11, 39, 239]. Nevertheless, the results obtained are still discordant and the role of phosphorylation in cardiovascular tissues is still not well defined.

Phosphorylated STAT3 belongs mainly to the JAK/ STAT signaling pathway that is a multifunctional pathway that regulates immunity, cell division, cell death and cell differentiation [173]. Different receptors can activate this pathway, including the Erythropoietin, Leptin and Angiotensin II receptors, as well as the Tumor Necrosis Factor Receptor 2 (TNFR2) and Gp130. The latter is a common receptor for the cytokines of the Interleukin 6 (IL-6) family including IL-5, IL-6, IL-11, Oncostatin M, Leukemia Inhibitory Factor, and Cardiotrophin 1. Upon ligand binding, the receptor undergoes multimerization that brings JAK proteins associated with the receptor cytoplasmic tail close together, allowing trans-phosphorylation. The activated JAK proteins phosphorylate the YXXQ sites on the receptor's cytoplasmic domain. These sites are recognized by the SH2 domain of STAT3, which will be in turn phosphorylated by JAKs on Y705 of the TAD.

The phosphorylation of Y705 is the crucial event needed to induce the dimerization of STAT3. STAT3 dimers move into the nucleus and regulate the transcription of different genes through the DBD. Y705 phosphorylation of STAT3 occurs as consequence of the stimulation by various cytokines, such as IL-6 and Interferon $\gamma$ (IFN $\gamma$ ), as well as growth factors, such as Fibroblast Growth Factor and Epidermal Growth Factor (EGF) [249]. Therefore, the induction of these pathways stimulates the phosphorylation of Y705, which subsequently leads to dimerization and translocation of the protein into the nucleus and constitutes the canonical pathway of STAT3 activation (Fig. 2).

It has been reported that mitogen-activated protein kinase (MAPK) family members including extracellular receptor kinase 1/2 (ERK1/2), c-Jun N-terminal kinase (JNK), and p38 can phosphorylate STAT3 at S727 [66]. Intriguingly, ERK1/2 is activated upon growth factors and cytokine stimulation and provides cardioprotection in IR settings via the RISK pathway activation [213]. Yet, JNK and p38 are known to be activated upon stress conditions and inflammatory cytokines, such as TNF $\alpha$, which is also involved in SWOP [40] and SAFE (see below, "STAT3 in the SAFE Pathway"). Interestingly, p38 is known to be a mediator of IRI, while JNK may have a dual effect, since evidence of JNK participating in myocardial damage [175] or in cardioprotection [185] have been reported.

Other serine/threonine kinases that are able to phosphorylate $\mathrm{S} 727$ are protein kinase $\mathrm{C}$ (PKC $\varepsilon$ and PKC $\delta$ isoforms), mammalian target of rapamycin (mTOR) and cyclin dependent kinase 5 (CDK5) [252]. Of note, the activation of $\mathrm{PKC} \varepsilon$ before ischemia protects mitochondrial function and reduces apoptosis, mimicking $\mathrm{IPreC}$, whereas it seems that the inhibition of $\mathrm{PKC} \delta$ during reperfusion protects the heart from IR injury. Nevertheless, conflicting studies have suggested that PKC $\delta$ activation plays a protective role in IR injury and that PKC $\delta$ knockout (KO) mice exhibit increased myocardial ischemic injury [146]. Moreover, it has been suggested that the activation of PKC $\delta$ before ischemia triggers a protective effect against myocardial IR alterations in both isolated perfused rat hearts and cultured cardiomyocytes [4].

In cancer cells, S727 phosphorylation has been observed during the canonical STAT3 activation, where it may have a role in enhancing the transcriptional activity of STAT3, for example by recruiting cofactors, such as the histone acetyltransferase $\mathrm{p} 300 / \mathrm{CBP}$ or by promoting the homodimer formation [3]. Yet, some works have shown that phosphorylation of S727 drives a reduction of the levels of Y705 phosphorylation in cancer cell lines. Yang et al. [234] demonstrated that the phosphorylation of S727 triggers the dissociation between pY705 and the SH2 domain of STAT3, thereby disrupting dimer formation. The phosphorylation of S727 enhances the dephosphorylation of Y705 by recruiting phosphatase TC45, therefore, limiting the duration of STAT3 transcriptional activity in a human liver cancer cell line (HepG2) [234]. Similar studies are lacking in cardiac cells. 
Table 1 Post-translational modifications of STAT3

\begin{tabular}{|c|c|c|c|}
\hline $\begin{array}{l}\text { Post-transla- } \\
\text { tional modifica- } \\
\text { tions }\end{array}$ & STAT3 site & Effects & Reference \\
\hline \multirow[t]{42}{*}{ Phosphorylation } & Y705 & $\begin{array}{l}\text { Dimerization and translocation of the protein into the nucleus and constitutes the canonical } \\
\text { pathway of STAT3 activation }\end{array}$ & [249] \\
\hline & Y705, S727 & Promotes oncogenic activity of RhoA & [11] \\
\hline & S727 & Negatively modulates STAT3 Y705 phosphorylation & [36] \\
\hline & S727 & Extends the function of mTOR, including transcriptional regulation & [239] \\
\hline & S727 & $\begin{array}{l}\text { Inactivates activated STAT3 leading to both pY705 dephosphorylation and post-activation } \\
\text { nuclear export }\end{array}$ & [234] \\
\hline & Y705, S727 & $\begin{array}{l}\text { Stimulates respiration and inhibits calcium-induced MPTP opening, contributing to cardio- } \\
\text { protection }\end{array}$ & {$[20]$} \\
\hline & S727 & Interacts with GRIM-19 to facilitate STAT3 mitochondrial localization & [210] \\
\hline & S727 & Activates complex I and II & [225] \\
\hline & S727 & Increases mRNA for complex I subunits and decreases ROS generation & [243] \\
\hline & Y705 & Increases mitochondrial respiratory capacity and biogenesis & [1] \\
\hline & Y705, S727 & Regulates ER Ca2 + homeostasis & [9] \\
\hline & S727 & Regulates mitochondrial metabolism & [201] \\
\hline & S727 & Moderates ROS levels in the post-ischemic phase & [229] \\
\hline & Y705 & Reduces infarct size in LAD-ligated pig hearts & [100] \\
\hline & Y705 & Increases $\mathrm{Ca} 2+$ retention capacity, preserves complex 1 respiration and reduces infarct size & [79] \\
\hline & S727 & Attenuates myocardial IR injury & [250] \\
\hline & Y705 & Regulates cardiomyocyte survival and remodelling & [49] \\
\hline & Y705 & Reduces infarct size in LAD-ligated pig hearts & [191] \\
\hline & Y705 & Reduces infarct size and improves lefte ventricle (LV) diastolic pressure & {$[82]$} \\
\hline & Y705 & Reduces IR injury in isolated rat hearts & [38] \\
\hline & Y705 & $\begin{array}{l}\text { Involved in efferent vagal nerve activation and spleen stimulation, releasing humoral cardio- } \\
\text { protective substances }\end{array}$ & [133] \\
\hline & Y705 & $\begin{array}{l}\text { Less vacuolization of mitochondria in the children undergoing open heart surgery and } \\
\text { RIPreC attenuating myocardial IRI }\end{array}$ & [230] \\
\hline & Y705 & Determines hypothermia-induced protection in $\mathrm{H} 9 \mathrm{c} 2$ cells & {$[88]$} \\
\hline & Y705 & Reduces infarct size in LAD-ligated rat hearts & [45] \\
\hline & Y705 & Reduces infarct size in LAD-ligated rat hearts & {$[62]$} \\
\hline & Y705, S727 & Anti-apoptotic effects on cardiomyocytes & [187] \\
\hline & Y705 & Ameliorates the contractile force in human atrial trabeculae exposed to $H / R$ & {$[125]$} \\
\hline & Y705 & Reduces infarct size in in-vivo mouse hearts & [7] \\
\hline & Y705 & Reduces infarct size in in-vivo mouse hearts & {$[160]$} \\
\hline & Y705 & Attenuates cardiac fibrosis by regulating the macrophage polarization & {$[123]$} \\
\hline & Y705 & Reduces infarct size in isolated rat hearts & [193] \\
\hline & Y705, S727 & Improves LV contraction and decreases expression of pro-apoptotic proteins & [47] \\
\hline & Y705 & Reduces IR injury in ex-vivo and in-vitro models & {$[53]$} \\
\hline & S727 & Reduces IR injury in isolated mice hearts & [197] \\
\hline & S727 & Regulates mitochondrial respiration in in-vivo model & [220] \\
\hline & S727 & Mediates cardioprotection as a modulator of ETC activity in the mitochondria & [206] \\
\hline & S727 & Reduces infarct size in mice & {$[18]$} \\
\hline & Y705 & Reduces hypertrophy in rat model & [29] \\
\hline & S727 & Attenuates diabetic rat heart IR injury & [217] \\
\hline & Y705 & Limits diabetic cardiomyopathy in in-vivo and in-vitro models & [203] \\
\hline & S727 & Reduces infarct size in diabetic rats & [131] \\
\hline & Y705 & Reduces infarct size in rats & [124] \\
\hline
\end{tabular}


Table 1 (continued)

\begin{tabular}{|c|c|c|c|}
\hline $\begin{array}{l}\text { Post-transla- } \\
\text { tional modifica- } \\
\text { tions }\end{array}$ & STAT3 site & Effects & Reference \\
\hline \multirow[t]{4}{*}{ Acetylation } & $\begin{array}{l}\text { K49, K87 (N-ter- } \\
\text { minus) and K685 } \\
\text { (SH2 domain) }\end{array}$ & $\begin{array}{l}\text { Enhances STAT3-mediated gene transcription and protects cardiomyocytes } v s \text { doxorubicin- } \\
\text { oxidative stress }\end{array}$ & [91] \\
\hline & K370, K383 & Improves mitochondrial morphology and function in neonatal mouse cardiac myocytes & {$[156]$} \\
\hline & K685 & $\begin{array}{l}\text { Induces Y705 phosphorylation transcriptional activity of STAT3 by increasing and dimer } \\
\text { stability in prostate cancer cell line (PC3) }\end{array}$ & [241] \\
\hline & K87 & Favors the translocation and mitochondrial functions of STAT3 in starved cancer cells & [232] \\
\hline \multirow[t]{2}{*}{ Methylation } & K140 dimethylation & Decreases STAT3-dependent transcription in A4 cancer cells & [233] \\
\hline & K180 trimethylation & $\begin{array}{l}\text { Stimulates STAT3 phosphorylation and transcriptional activity in glioblastoma and prostate } \\
\text { cancer cells }\end{array}$ & {$[95]$} \\
\hline Sulfydration & $\begin{array}{l}\text { no direct sulfydra- } \\
\text { tion detected on } \\
\text { STAT3 }\end{array}$ & $\begin{array}{l}\text { Activates STAT3 by Y705 phosphorylation and protects cardiomyocytes vs doxorubicin- } \\
\text { oxidative stress }\end{array}$ & [228] \\
\hline S-nitrosylation & $\mathrm{C} 259$ & Blocks Y705 phoshorylation in microglial cells & [96] \\
\hline Ubiquitination & K97 & $\begin{array}{l}\text { Induces the recruitment of BRD4 and the transcription of anti-apoptotic genes in HepG2 } \\
\text { cells }\end{array}$ & {$[174]$} \\
\hline
\end{tabular}

\section{Acetylation}

In response to stimulation by growth factors and cytokines, STAT3 can also be acetylated on multiple lysine residues (K) by histone acetyltransferase $\mathrm{CBP} / \mathrm{p} 300$. Acetylation at $\mathrm{K} 49$, K87 (N-terminus) and K685 ( $\mathrm{SH} 2$ domain) enhances STAT3-mediated gene transcription and protects cardiomyocytes from doxorubicin (DOXO)-oxidative stress [91]. It has been also observed that acetylation in K87 may favor the translocation in mitochondria of STAT3 in starved cancer cells after serum reintroduction or insulin stimulation [232]. Yet, acetylation in K685 induces the transcriptional activity of STAT3 by increasing tyrosine phosphorylation and dimer stability in prostate cancer cell line (PC3) [241]. STAT3 acetylation is also involved in the improvement of mitochondrial morphology and function in neonatal mouse cardiac myocytes [156]. It has been shown that after resveratrol treatment, STAT3 acetylated in K685 can silence tumor suppressor genes by recruiting DNA methyltransferase 1 to their promoters [120]. Yet, the nicotinamide adenine dinucleotide (NAD)-dependent silent information regulatory protein (SIRT) 1 can deacetylate STAT3 in the liver [159]. Of note, SIRT1-induced deacetylation leads to reduced mitochondrial localization and function of phosphorylated STAT3 in murine embryonic fibroblast cells [15].

\section{Methylation}

In the nucleus, STAT3 methylations have been described on the K140 or K180 residues, with different effects on STAT3 activities. Histone methyltransferase SET9, a histone-modifying enzyme, is capable of methylating STAT3 on K140, leading to modulation of transcriptional activation of target genes in A4 cancer cells [233]. On the other hand, the enhancer of zeste homolog 2 (EZH2) component of the polycomb 2 complex determines K180 tri-methylation, which is essential for maintaining STAT3 phosphorylation and transcriptional activity in glioblastoma and prostate cancer cells [90]. The majority of studies on acetylation and methylation have been performed on mammalian cancer cells.

\section{Glutathionylation, oxidation, S-nitrosylation and sulfhydration}

STAT3 can be oxidized, S-nitrosylated, sulfhydrated and glutathionylated on multiple cysteine residues, suggesting that STAT3 controls redox homeostasis and ROS signaling induced by cytokines and growth factors. Using antioxidants in studying the effects of cytokines on cells or in stimulating cells (fibroblasts and A-431 carcinoma cells) with $\mathrm{H}_{2} \mathrm{O}_{2}$, ROS have been shown to play a signaling role in the control of JAK, STAT3 and STAT5 [188]. The activation of STAT3 and STAT5 by ROS upon cytokine or growth factor treatment can also determine the activation of NADPH oxidase (Nox) in human aortic smooth muscle cells [92] and in cancer cells [240]. In particular, ROS inhibit STAT3 transcriptional activity, either downstream of the IL-6 signal or in conditions of oxidative/nitrosative stress [107, 132, 196, 231]. Of note, moderate ROS production downstream of growth factors such as insulin-like growth factor 1 (IGF1) and EGF can activate JAK kinases and enhance STAT3 phosphorylation and its nuclear activity $[35,110$, $122,188]$. STAT3 oxidation can be observed downstream of cytoplasmic thiol peroxidase peroxiredoxin-2 (Prx2) [196]. 
This limits ROS toxic effects, but impairs IL-6-induced and STAT3-mediated transcription. STAT3 sulfhydration favors STAT3 activation by $\mathrm{Y} 705$ phosphorylation and protects cardiomyocytes from DOXO-oxidative stress [228]. Finally, S-nitrosylation at C259 blocks Y705 phoshorylation in microglial cells [96] and ubiquitination at K97 induces the recruitment of BRD4 and the transcription of anti-apoptotic genes in HepG2 cells. Thus, the inhibition of the STAT3 mono-ubiquitination-BRD4 pathway may be useful for the treatment of STAT3-dependent tumors [174].

All in all, it appears that a cross-talk between oxidative and non-oxidative modifications of STAT3 can influence canonical and unconventional STAT3 activities, including cell proliferation and survival. The complex functions of STAT3 in redox homeostasis have recently been reviewed $[8,102,134]$.

\section{STAT3 in the SAFE Pathway}

Post-translational modification of STAT3 is a pivotal step in the SAFE pathway in which TNF $\alpha$ and its receptors play key roles. As said this pathway can be activated in conjunction with the RISK pathway and it has been proposed to play a more important role in larger mammals $[70,79,189$, 190]. Here we point out some aspects of SAFE in relation to STAT3.

First, it has been observed that in rodent hearts TNF $\alpha$ protects against IR in a dose-dependent manner [43, 112, 117]. Besides TNF $\alpha$, other agonists have been suggested in SAFE signaling, including high density lipoprotein (HDL), sphingosine-1-phosphate (S1P), IL-10, insulin and stromal cell-derived factor-1 alpha [26, 27, 46, 52], to name a few. Furthermore, TNF $\alpha$ emerged as an important cardioprotective endogenous factor released by cardiomyocytes during IPreC and IPostC maneuvers [113, 118]. Two isoforms of the TNF $\alpha$ receptor have been described in the heart, the TNFR1 and the TNFR2. Intriguingly, exogenous TNF $\alpha$ induces cardioprotection in TNFR1 KO mice, but is unable to protect TNFR2 KO mice, thus suggesting that cardioprotection is mediated by TNFR 2 activation [114]. In addition, it appears that TNF-receptor-associated-factor 2 (TRAF2) is the downstream target of TNFR2 in mice [24]. Yet, TRAF2 is able to activate the formation of the S1P via sphingosine kinase 1 (SK1) activity [5] and the protective effect of TNF $\alpha$ is blunted in the presence of the sphingolipid pathway inhibitor, $\mathrm{N}$-oleoylethanolamine [28]. These data suggest that S1P can act as a downstream target of TNF $\alpha / T N F R 2 / T R A F 2$ to confer cardioprotection [117]. TNF $\alpha$ binding to its specific receptors activates the JAK-STAT3 pathway. In particular, JAK2 phosphorylates and makes a docking site for STAT3 which, after phosphorylation is activated (Fig. 2). Of note, it has been proposed that TNF $\alpha$ is able to induce $\mathrm{Y} 705$ phosphorylation even if the interaction between TNFR2 and JAK2 is still uncovered [63]. Indeed, this interaction could result in the activation of intracellular SK1 and S1P production in cell lines [5]. Following the binding of TNF $\alpha$ to TNFR2, the activation of TRAF2 could upregulate SK1, which in turn could catalyze the formation of intracellular S1P and the subsequent activation of JAK-STAT3 (Fig. 2).

In the next chapter, we analyze the mitochondrial function affected by IR and the role of STAT3 in affecting mitochondria function. Indeed, mitochondrial targeting is essential in the SAFE pathway.

\section{Mitochondrial functions affected by IR}

Before to analyze the mitochondrial STAT3 role we briefly describe the role of mitochondria in IRI (for more details the reader is redirect to other review, e.g., $[69,76-78,162$, 164],).

Under physiological conditions, mitochondria guarantee energy requirements, while under stressful conditions, they represent the judges of cell fate between life and death [128]. The heart is a high-energy-consuming organ as cardiomyocytes contain a large number of mitochondria (about 30-40\% in volume). Therefore, the heart will be heavily affected by the inefficient supply of oxygen and the consequent alteration of the mitochondrial status.

During ischemia, the metabolism of myocardial tissue, initially mainly aerobic, turns towards an anaerobic phenotype. The mitochondrial metabolism is compromised by a drop in intracellular $\mathrm{pH}$ and a strong reduction in the ATP production [74]. ATP depletion causes a sensible reduction of the activity of $\mathrm{Na}^{+} / \mathrm{K}^{+}$-ATPase, and other ion pumps fundamental for the maintenance of the physiological mitochondrial membrane potential $(\Delta \Psi \mathrm{m})$, including the $\mathrm{Na}^{+} /$ $\mathrm{H}^{+}$exchanger, the $\mathrm{Na}^{+} / \mathrm{Ca}^{2+}$ exchanger and the L-type $\mathrm{Ca}^{2+}$ channel [202]. In particular, the activation of L-type $\mathrm{Ca}^{2+}$ channel contributes to $\mathrm{Ca}^{2+}$ overload, with subsequent activation of nucleases, proteases and phospholipases. Another crucial event characterizing both ischemia and reperfusion is the ROS production, which derives from altered activity of both ETC and enzymes, such as xantine oxydase (XO), NADPH oxidase, cytochrome $\mathrm{P} 450$ oxidases, uncoupled nitric oxide synthase (NOS), and monoaminooxidase (MAO) [42]. All of these changes lead to depression of respiratory chain complex activity, inappropriate oxidative phosphorylation and ATP synthesis by F1F0-ATPase, that in turn determine a reduction in $\Delta \Psi \mathrm{m}$, an additional $\mathrm{Ca}^{2+}$ overload, the ROS-induced ROS release (RIRR) phenomenon, mitochondrial swelling and cytochrome $c$ release promoting cell death [180, 202].

Upon reperfusion, and in particular immediately in the first phase, compared to ischemia, ROS production may lead to the peroxidation of mitochondrial respiratory complexes, 
including the SH groups of complex I and cardiolipin, which is needed for complex III and complex IV activity. In IR setting the F1F0-ATPase not only reduces the production of ATP but may also reverse its operation by hydrolyzing the ATP present as the proton motive force that pushes the ETC is dissipated [143]. Therefore, the loss of ATP during IR is further exacerbated [67]. Of note, F1F0-ATPase pump is recognized as the main component of mPTPs [14]. Despite the controversy surrounding the components that make up mPTPs, there is greater consensus on the triggers that induce their opening. Conditions such as $\mathrm{Ca}^{2+}$ overload, excessive ROS production, ATP depletion and an increase in inorganic phosphate contribute to a large extent to their opening [162]. mPTPs opening is favored by $\mathrm{pH}$ recovery during reperfusion [89] with a subsequent collapse of the inner membrane, decoupling of the respiratory chain, arrest of mitochondrial ATP synthesis, and ultimately mitochondrial swelling, rupture, and cell death. The pharmacological inhibition of mPTPs opening at the beginning of reperfusion can attenuate cardiomyocyte death and reduce myocardial IS $[25,162]$. Of note, F1F0 ATPase and mPTPs may also have a role in triggering IPreC $[68,169]$.

As said above and as reported in Fig. 1, three main signaling cascades that converge to mitochondria have been identified in the context of IPreC and IPostC. It has been proposed that glycogen synthase kinase-3 $\beta$ (GSK-3 $\beta$ ) acts directly on components on the mPTPs as well as on Bcl-2 family proteins [164]. Moreover, the cGMP-PKG pathway may lead to the phosphorylation of mitochondrial PKC 1 1, which promote the opening of the mitochondrial ATP-sensitive $\mathrm{K}^{+}$ channel ( mitoK $_{\text {ATP }}$ ) [55]; once opened, these channels allow increased uptake of $\mathrm{K}^{+}$in the matrix, leading to alkalinization of the mitochondrial membrane. To counterbalance this event, Complex I of ETC increases its activity and produces more superoxide and its products $\mathrm{H}_{2} \mathrm{O}_{2}$ and hydroxyl anion radical. The increased ROS are able to activate another PKC, PKCE2, which in turn will inhibit the mPTPs with a phosphorylation-dependent reaction, thereby preserving mitochondrial functionality [164].

Mitochondria are dynamic organelles that continually change their shape by undergoing quality control mechanisms, that include mitochondrial fission, fusion and mitophagy, a specialized form of autophagy; these are fundamental processes to maintain mitochondria turnover and assure metabolic need of cardiomyocytes [76, 162]. Upon IR stressful conditions, mitochondria may activate these quality control mechanisms. Thus removing defective mitochondria and restoring the energetic balance, to protect cardiomyocytes against IRI. Mitophagy should be finely regulated to maintain a favorable balance between dying mitochondria and new functional mitochondria, which should restore ATP production. During IR excessive mitochondrial fission may lead to cardiomyocyte death. In particular, dynamin related protein-1 (DRP1), the regulator of mitochondrial fission, is able to recruit Bax/Bak and promotes the MPTP formation at the outer mitochondrial membrane, triggering cytochrome $\mathrm{c}$ release. In addition, mitochondrial fusion may provide a protective effect during IR, by counterbalancing the excessive mitochondrial fission, and equilibrating mitochondrial proteins and mitochondrial DNA (mtDNA) [104]. In this context, STAT3 may play a pivotal role (Fig. 2) as we describe below (see also "Effects of STAT3 on mitochondrial quality control").

\section{Effects of STAT3 on mitochondrial function}

STAT3 non-genomic functions raise still some questions about how, where, and when its action is exerted. In particular, in cardiac IRI models, mitochondria are the most interesting target of the investigation, since they are highly represented and can determine the life and death of cardiac cells. Besides mitochondrial quality control, ETC, $\Delta \Psi \mathrm{m}$, $\mathrm{Ca}^{2+}$ regulation, redox balance, and mPTPs status are promising targets that can be affected by STAT3 non-genomic function.

Localization of STAT3 in mitochondria. To investigate the role of STAT3 in mitochondria, it is necessary to verify its localization and how it is redirected and translocated in mitochondria. Even before the discovery of the SAFE pathway, several research groups studied the interaction of STAT3 with candidate proteins and their localization in mice and rats cardiomyocytes [65, 93, 229]. The interest started in the contest of cancer research, focusing on finding molecules able to interact and inhibit the transcriptional activity of STAT3, which is known to regulate cell growth and apoptosis and is constitutively active in various cancers [119]. Even if the cellular models are different, the identification of interactors of STAT3 has been the first step to understand the mechanisms promoting the mitochondrial localization of STAT3 in cardiac cells. Several evidences obtained with techniques, such as Yeast two-hybrid, co-immunoprecipitation, and immunofluorescence, suggest that the main mitochondrial interactor of STAT3 is gene associated with retinoid interferon-induced cell mortality 19 (GRIM19) [140].

Phosphorylation of mitochondrial STAT3. Zhang et al. [244] found that the mutagenesis of S727 into alanine determines the suppression of the interaction with mitochondrial GRIM19 in HeLa cells. Therefore, phosphorylation of S727 sites has been proposed as necessary for mitochondrial localization (Fig. 2). Nevertheless, the timing and nature of STAT3 phosphorylation should still be determined, to understand if the phosphorylation occurs outside or inside the mitochondria and if phosphorylation of S727 is fundamental in determining the import in mitochondria. Boengler et al. [20], among others, found that STAT3 phosphorylated at 
both Y705 and S727 and co-immunoprecipitated with translocase of the outer membrane 20 (TOM20) in mitochondria extracted from the rat left ventricle.

Import into mitochondria and interacting mitochondrial proteins. Zhang et al. [244] showed that GRIM19, in different cancer cell lines, interacts specifically with STAT3 but not with other STAT proteins, such as STAT1 and STAT5A. This selectivity may be due to the differences that STAT family members bear in the TAD, which deletion prevents the co-immunoprecipitation of these two proteins. Although the aim of Zhang et al. [244] was to demonstrate that GRIM19 was able to inhibit the genomic function of STAT3 in the tumorigenesis progression, subsequently Tammineni et al. [210] found that STAT3 is enriched in the inner mitochondrial membrane isolated from rat heart and suggested that GRIM19 influences STAT3 integration into complex I. Indeed, GRIM19 was found to promote STAT3 import into mitochondria and to favor STAT3 integration into complex I. As said, these two events may depend on the S727 site of STAT3 C-terminus. Indeed, in mitochondria from rat hearts, the deletion of the $\mathrm{C}$-terminus and the mutation of serine 727 into alanine (S727A) abolished the import of STAT3 and the assembly into complex I [210]. Even if STAT3 lacks the mitochondrial targeting sequence required for the mitochondrial import, TOM20 has been proposed to recognize STAT3 and mediate its translocation inside the mitochondria [20].

Despite these evidences, some studies did not find STAT3 in the mitochondrial fraction of mice hearts [65]. Some of these works investigated the hypothesis that STAT3 may exert its non-genomic function in other non-nuclear sites, such as in the ER. For instance, Su et al. [201] demonstrated that STAT3 is present in the mitochondrial-associated ER membrane (MAM) of different tissues (liver, lungs, brain). A data confirmed by Avalle et al. in cancer cell lines [9] (see below "Effects of STAT3 on $\mathrm{Ca}^{2+}$ regulation").

\section{Effects of STAT3 on mitochondrial ETC}

As mentioned before, mitochondrial damage occurring during ischemia can be partially explained by the alteration of ETC functionality, followed by enhanced ROS generation during reperfusion [205]. It is possible to induce cardioprotection by targeting ETC complexes and regulating mitochondrial respiration. STAT3 has been shown to interact with ETC complex I and II, preserving their activity in mitochondria from mice hearts and enhance ATP production in human cancer cells $[61,225]$. As result, aerobic cellular respiration would be optimized, and ROS formation would be under control (Fig. 2). Particularly, Wegrzyn et al. [225] considered the role of STAT3 in cellular respiration. First, they verified the mitochondrial and submitochondrial location of STAT3 in cells isolated from mouse heart, brain, kidney, spleen as well as human cell lines. One-tenth of the cellular STAT3 has been found in the mitochondrial fraction of these cells. STAT3 and GRIM19 resisted the proteinase $\mathrm{K}$ treatment of isolated mitochondria, indicating that they may be located in the inner membrane or the matrix, rather than in the outer membrane. STAT3 co-immunoprecipitated with components of complex I and II, which activity was then measured in the absence and presence of STAT3. Cardiomyocytes from STAT3-deficient mice showed a decreased rate of $\mathrm{O}_{2}$ consumption as well as reduction of complex I and II activity, but not complex III. In STAT3-deficient pro-B cells the loss of complex I and II activity was restored by both full-length STAT3 and by MLS-STAT3, the mitochondrial form of STAT3. The latter is obtained by adding the mitochondrial targeting sequence of cytochrome $\mathrm{c}$ oxidase subunit VIII to STAT3. A mutagenesis study of MLS-STAT3 then revealed that the S727, but not the Y705 site was fundamental to mediate the activation of complex I and II [225].

However, it is still unclear whether the control of mitochondrial localization, complex I/II association, or other step might be responsible of the STAT3 regulation of the respiration [154]. Whether such a regulation pertains to STAT5 in different species is alternatively discussed [245].

Direct interactions between STAT3 and complex III and IV were not found; however, the existence of mitochondrial respiratory supercomplexes formed by complex I, III, and IV [128] does not allow to rule out the influences of STAT3 on these supercomplexes. Contradictory results are reported regarding the ability of STAT3 to decrease ROS generation by complexes I and III of the ETC in mitochondria from mice left ventricular tissue [21]. The low ratio between complexes I and II and STAT3 in mitochondria of porcine and murine hearts [170] is against the hypothesis that STAT3 might be a structural component of these complexes. Therefore, further analyses are required to determine the nature of the interaction between STAT3 and the proteins of the ETC.

Other studies investigated whether different molecules improve the recovery of mitochondrial function after IRI through STAT3 signaling within mitochondria. For instance, Zhang et al. [243], used Zinc either on isolated rat hearts or H9c2 cardiomyoblasts subjected to IR or Hypoxia/Reoxygenation $(H / R)$, respectively. They observed that Zinc treatment leads to increased phosphorylation of STAT3 at S727 compared to Y705. Yet, the balance of cytosolic and mitochondrial STAT3 was in favor of the latter, suggesting that the phosphorylation of S727 could direct STAT3 towards mitochondria. Moreover, it has been shown that Zinc-induced S727 phosphorylation is involved in the enhancement of mitochondrial oxidative phosphorylation. Particularly, in isolated rat hearts exposed to IR, Zinc induced a sensible improvement of the rate of respiration, 
which determined an increased ATP level and citrate synthase activity. These data are supported by an increase in mRNA for complex I subunits and a decrease in ROS generation [243].

The mechanism by which STAT3 interacts with Complexes I and II is still unknown; there is contrasting evidence about whether mitochondrial STAT3 can modulate the levels of mRNA of these complexes, but in the majority of the cases, the mRNA levels are unchanged in presence or absence of mitochondrial STAT3. Intriguingly, STAT3 was found to bind mtDNA in several cell types and to interact with mitochondrial transcription factor TFAM in keratinocytes, where it regulates the level of some mitochondrialencoded transcripts, such as NADH dehydrogenase 5/6 and cytochrome $b$ [142]. Of note, the prevention of mtDNA degradation has proven to be cardioprotective in in vivo and ex vivo rat hearts [237]. Nevertheless, to the best of our knowledge, despite STAT3 binding to mtDNA, no evidence has been reported on the role of STAT3 in influencing mitochondrial-encoded transcript and/or mtDNA degradation in the context of cardioprotection. Further investigation is required to elucidate the exact pathway by which STAT3 affects mitochondrial ETC.

\section{Effect of STAT3 on ROS generation}

The mitochondrial redox state is determined by the balance between the production of reactive species by the ETC and the other sources of ROS indicated above on the one hand and the scavenging of ROS by antioxidant enzymes on the other hand.

For instance, during IR events, ETC is altered and consequently, ROS production is increased and further sustained by the RIRR. This leads to cardiolipin peroxidation at the inner membrane that favors mPTPs opening and cytochrome c release from mitochondria, promoting apoptosis [212]. Studies in cardiomyocytes showed that DOXO treatment caused a reduction of the complex I in mitochondria, as well as increased production of ROS [247]. The cardiacspecific overexpression of STAT3 led to a decreased toxicity of DOXO in mice and in primary ventricular murine cardiomyocytes [106, 177], suggesting that STAT3 may be able to attenuate ROS formation, even if its precise mitochondrial function has not yet been discovered. Studies report a strong inhibition of complexes I and II in cardiac tissues [225] and a low membrane potential, a decreased ATP level and an increased ROS formation in the absence of mitochondrial STAT3 in astrocytes [181].

It is not clear how STAT3 can promote mitochondrial respiration and at the same time minimize ROS formation. Szczepanek et al. [205] speculate that during ischemia STAT3 is able to reduce the levels of superoxide produced by complex I, and to address, decreasing cardiolipin oxidation, the superoxide towards the mitochondrial matrix, thereby protecting the inner membrane and preventing the release of cytochrome c. This speculation was supported by the observation that cardiomyocytes overexpressing mitochondrialtargeted STAT3 had reduced ROS levels in comparison with wild type mitochondria upon ischemia. Additional evidence supporting that STAT3 is able to keep ROS under control is provided by Boengler et al. [20], who treated mitochondria extracted from rat left ventricles with the STAT3 inhibitor Stattic. In this case, the inhibition of STAT3 induced a dosedependent increase in ROS formation from complex I, which was coupled with lower ATP production and $\mathrm{Ca}^{2+}$ retention capacity. Nevertheless, further research is needed as Stattic is not specific for mitochondrial STAT3 [183]. Moreover, we cannot rule out that STAT3 genomic function contributes to reducing ROS formation by altering the transcription of genes encoding scavenging proteins. An interesting study about the relationship between STAT3 and ROS is provided by Abid et al. [1]. They demonstrated that IL-6 exposure activates the canonical STAT3 pathway in myotubes favoring mitochondrial ROS formation and STAT3 Y705 phosphorylation, determining a sort of positive feedback between these two events. As a result, mitochondrial respiratory capacity and biogenesis were acutely increased. However, a decline in respiration and a further elevation in ROS and oxidative stress was observed when IL- 6 exposure was sustained [1].

\section{Effects of STAT3 on mPTPs opening}

The most critical challenge to safeguard cardiac cell function during IR stress is to maintain the mitochondria integrity. As mentioned before, the opening of mPTPs is a crucial step leading to cell death and it occurs mainly during reperfusion of cardiac tissue, as a consequence of the damage caused by ROS and $\mathrm{Ca}^{2+}$ overload [108]. The point is discussed by Boengler et al. [20], who investigated the role of STAT3 in isolated mitochondria from cardiomyocytespecific STAT3 ${ }^{-1-}$ mice and in isolated rat heart mitochondria using the inhibitor Stattic. Mitochondria isolated from STAT3 $^{-/-}$hearts undergo mPTPs opening upon exposure to lower $\mathrm{Ca}^{2+}$ levels compared to STAT3 ${ }^{+/+}$hearts [20]. Therefore, it can be hypothesized that STAT3 ${ }^{-1-}$ mitochondria are more susceptible to reperfusion-induced damage when $\mathrm{Ca}^{2+}$ overload triggers mPTPs opening (Fig. 2). Indeed, IPreC and IPostC, which rely on the limitation of mPTPs opening at the beginning of reperfusion, do not trigger cardioprotection in mouse STAT3 ${ }^{-/-}$hearts $[113,194]$. The reason behind this protective role of STAT3 is still unknown, but some possible hypotheses relate to the interaction of STAT3 with cyclophilin $\mathrm{D}(\mathrm{CypD})$, a mitochondrial protein identified as a regulator of MPTPs [151]. This binding is mediated by the amino terminus of STAT3, suggesting that other domains (amino 
acids $1-330$ of STAT3) in mitoSTAT3 are relevant for its non-canonical mitochondrial role. The interaction STAT3CypD occurs in the mitochondria with subsequent reduction of mitochondrial ROS production after oxidative stress [151]. As said above, another hypothesis is that STAT3 binds to the NTD of the mitochondrial $\mathrm{Ca}^{2+}$ uniporter (MCU) to reduce mitochondrial $\mathrm{Ca}^{2+}$ overload and thus ROS production in rat hearts and cardiomyocytes [229]. Nevertheless, a reduction of ROS formation may limit mPTPs opening and the RIRR phenomenon [212].

\section{Effects of STAT3 on $\mathrm{Ca}^{2+}$ regulation}

Calcium regulation is one of the main events that denote the cell functionality; therefore, its concentration in different subcellular compartments is finely controlled. In the ER, $\mathrm{Ca}^{2+}$ pump (SERCA), IP3R and their relative ryanodine receptors represent the gates that allow the entry and the release of $\mathrm{Ca}^{2+}$, respectively [32], while in the mitochondria, $\mathrm{Ca}^{2+}$ concentration is important to regulate the activity of enzymes, the rate of respiration and to maintain MPTPs status. It has been proposed that STAT3 may have an important role in the closed relationship between ER and mitochondria. In this regard, Avalle et al. [9] showed that STAT3 interacted with IP3R3 on the ER and that its mutation in S727, but not in Y705, determined an excessive release of $\mathrm{Ca}^{2+}$ in the cytosol of breast cancer cell lines. They explained this observation by demonstrating that STAT3 promoted IP3R3 proteasomal degradation. Moreover, STAT3 silencing in STAT3-dependent MDA-MB-468 and -231 cells also significantly increased $\mathrm{Ca}^{2+}$ content and release from the ER [9]. On the other hand, in MDA-MB-453 or T47D cells, in which STAT3 is not active, the release of $\mathrm{Ca}^{2+}$ was not modified by the silencing of STAT3. Therefore, in STAT3-dependent cells, treatment with $\mathrm{H}_{2} \mathrm{O}_{2}$ or menadione increased $\mathrm{Ca}^{2+}$

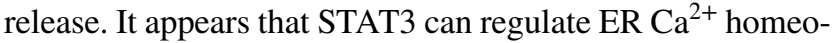
stasis when phosphorylated on both Y705 and S727 by localizing to the ER and MAM, where it physically interacts with the IP3R3 $\mathrm{Ca}^{2+}$ channels [9] (Fig. 2). IP3R is also known to mediate the interaction between MAM and voltage-dependent anion channels (VDAC) on the mitochondrial membrane [32]; therefore, is not excluded that STAT3, which has been found in the MAM context [201], may be involved in this cross-talk. In other words, the preservation of $\mathrm{Ca}^{2+}$ homeostasis by S727-phosphorylated STAT3 in the ER represents an indirect mechanism of mitochondrial metabolism regulation. Another evidence of STAT3 $\mathrm{Ca}^{2+}$ regulation is provided by Yang et al. [235], who examined the alterations of mitochondrial $\mathrm{Ca}^{2+}$ in $\mathrm{STAT}^{+/+}$and $\mathrm{STAT}^{-/-} \mathrm{CD} 4$ cells under IL- 6 stimulation. They found that IL- 6 promoted an increase in mitochondrial $\mathrm{Ca}^{2+}$ and that STAT3 was able to reduce its mitochondrial concentration, by promoting the $\mathrm{Ca}^{2+}$ export to the cytosol. This action was independent of the transcriptional activity of STAT3, but more likely elicited through mitochondrial STAT3.

It has been reported that MCU transports significant amounts of $\mathrm{Ca}^{2+}$ from the cytosol into mitochondria [51]. The activity of MCU may be influenced by STAT3. Indeed, it has been reported that during IPostC obtained with $\mathrm{H}_{2} \mathrm{O}_{2}$, STAT3 interacts with the N-Terminal Domain (NTD) of MCU in rat cardiomyocytes [229]. Moreover, a co-localization and interaction of STAT3 phosphorylated at S727 and MCU was observed in these cardiomyocytes. These results indicated that moderate ROS levels in the post-ischemic phase could activate STAT3 which inhibits the MCU via its interaction with the NTD of MCU to relieve mitochondrial $\mathrm{Ca}^{2+}$ overload [229].

\section{Effects of STAT3 on mitochondrial quality control}

TNFR2 activation protects cardiac myocytes against stress by upregulating optic atrophy 1 (OPA1) expression. This process was facilitated by $\mathrm{p} 300$-mediated STAT3 acetylation and STAT3/RelA interactions, leading to improvements in mitochondrial morphology and function [156]. Yet, א-opioid receptor activation promotes mitochondrial fusion and enhances myocardial resistance to ischemia and reperfusion injury via STAT3-OPA1 pathway [219]. Since mitochondrial quality control plays a vital role in cardioprotection, further investigations are needed to clarify the exact involvement of STAT3 in this process.

All in all, we can say that STAT3 plays a pivotal role in regulating mitochondrial function, fundamental organelles for the cardioprotection by conditioning procedures. Since STAT3 is central in the SAFE pathway, the activation of this pathway is necessary for the cardioprotective effect of ischemic conditioning in some species and conditions [19, 98, 101]. In the following Section we discuss these aspects.

\section{STAT3 in cardiac conditioning}

As mentioned in the introduction, here we update the role that STAT3 plays in the context of different conditioning strategies, including IPreC, IPostC, pharmacological/hypothermic conditioning and RIC. The latter can be induced before (RIPreC), during (RIPerC) or after (RIPostC) the myocardial infarcting ischemia (Fig. 1). In all these procedures the involvement of STAT3 has been described. Indeed, TNF $\alpha$ or STAT3 cardiomyocyte KO are not protected by ischemic conditioning stimuli, but it is still possible to induce pharmacological conditioning [113, 118, 194, 195]. Therefore, some differences among procedures and species exist, as we will see, for example, considering the parallels between STAT3 and STAT5. 


\section{STAT3 in ischemic preconditioning}

As said, IPreC, defined as non-lethal episodes of myocardial IR applied before an ischemic event, is the first conditioning maneuver discovered more than 35 years ago [153]. Clinical evidence of the efficacy of IPreC in human hearts, supported by parameters, such as attenuated ECG changes, reduced lactate and creatine kinase release, are provided by the review of Heusch and Rassaf [81].

The comprehensive article of Kleinbongard [100] compared IPreC, IPostC and RIPreC in relation to the phosphorylation of different proteins involved in cardioprotection, including STAT3, Akt and ERK1/2. The phosphorylation of STAT3 in Y705 occurred at both $10 \mathrm{~min}$ and $120 \mathrm{~min}$ of reperfusion post left anterior descending artery (LAD) ligature only in pig's hearts exposed to IPrec and not to IPostC nor RIPreC. Since any other signaling pathways were upregulated, STAT3 activation was associated with cardioprotective properties of IPreC in pigs.

The same result is confirmed by some other studies in pigs [57], but questioned by another study [200], in which the specific inhibition of ERK signaling and not STAT3, abrogated IPreC-mediated cardioprotection in pigs. Yet, Kwak et al. [109] reported that the protective mechanisms of sodium nitroprusside (SNP, $0.3 \mathrm{mM}$ ) preconditioning against high-concentration-SNP (1.5 mM)-induced apoptosis in H9c2 cardiomyoblasts was mediated by ERK1/2-STAT1/3 activation via PKC-dependent mechanisms. Indeed, in this model chelerythrine, a PKC antagonist, abolished the activation of both ERK1/2 and STAT1/3. Bolli et al. [23] used an inducible cardiomyocytes-specific STAT3 KO mouse to determine the role of STAT3 in mediating the IPreC-protection versus in vivo LAD ligation. In this study, IPreC upregulation of cardioprotective proteins, such as Heme oxygenase 1 and Cyclooxygenase- 2 and antiapoptotic proteins (Bcl-xL and Mcl-1, c-FLIPL and c-FLIPS), was abrogated in cardiomyocytes-specific STAT3 KO mouse [23]. These experiments by Bolli and coll. [23] provide insight on the fundamental role of STAT3 in inducing cardioprotection in the late phase of IPreC and, therefore, its deletion abrogates all of these protective effects.

\section{STAT3 in ischemic postconditioning}

IPostC refers to brief repeated cycles of ischemia and reperfusion that are applied at the ischemic site immediately after reperfusion [248]. IPostC may reduce IS, edema and improve left ventricle (LV) contractile properties in clinical studies [211]. However, other studies do not support these cardioprotective potentials (see below, "Some more considerations on mitochondrial STAT3 in IRI and cardioprotection" and "Effects of common risk factors and confounders on STAT3 cardioprotection").
The mechanisms of protection may be similar to IPreC, i.e., SAFE and RISK pathway, but IPostC protection may rely also on other pathways, which control redox state and $\mathrm{pH}$, as well as on mitochondrial players influenced by STAT3. In this regard, Heusch et al. [79] studied the phosphorylation of STAT3 and the mitochondrial activity in pig hearts subjected to IR followed by IPostC. In isolated mitochondria from postconditioned hearts, STAT3 phosphorylation in Y705 was increased and they observed increased $\mathrm{Ca}^{2+}$ retention capacity and preserved complex 1 respiration in comparison with mitochondria from non-conditioned hearts. All these effects, including the decreased IS were reverted with the use of AG490, a specific and potent inhibitor of the JAK2/STAT3 pathway.

Zhu et al. [250] found that IPostC, in primary rat ventricular cardiomyocytes exposed to $\mathrm{H} / \mathrm{R}$, is able to reduce H/R-induced cell damage, with concomitant enhancement of STAT3 phosphorylation S727 but not at Y705. These authors were interested in the involvement of 5' Adenosine Monophosphate-activated protein kinase (AMPK) in IPostC and they found that STAT3 phosphorylation was not affected by the inhibition of AMPK, as well as the protective effects of IPostC were not abrogated, suggesting that IPostC in vitro relies on STAT3 and this is independent of AMPK signaling. In vivo model of MI achieved with LAD occlusion gave similar results with IPostC, increasing the level of S727 but not Y705 phosphorylation of STAT3 [250]. Moreover, they compared IPostC to pharmacological postconditioning with Adiponectin and they found that while IPostC induced STAT3 activation by $\mathrm{S} 727$ phosphorylation, the latter activated/phosphorylated STAT3 in Y705, supporting the difference between ischemic and pharmacological conditioning. Interestingly, the combination of IPostC and Adiponectin conditioning provided additional protection in comparison with the conditioning alone, and promoted the phosphorylation of both sites of STAT3 [250]. This suggests that the integration of canonical pathway of STAT3 (transcription of antioxidant and anti-apoptotic genes) with the mitochondrial pathway (reduction of ROS production, mPTPs opening prevention, optimization of complex I activity) is able to provide maximal cardioprotection in vivo.

\section{STAT3 in remote ischemic conditioning}

Remote ischemic conditioning is performed by applying brief cycles of IR in a remote organ or tissue from the heart; it was demonstrated to protect the heart against subsequent ischemic events, not only in animal models, but also in humans and it is currently under studies in the clinic [33, 85, 171].

STAT3 signaling was activated in mice hearts subjected to LAD ligation, when RIPostC was applied in the left hind limb at the beginning of reperfusion [54]. Apoptosis and 
oxidative stress markers were decreased in the RIPostC group, but these protective effects were abrogated when mice underwent AG490 pre-treatment and STAT3 was inhibited. Accordingly, Billah and colleagues [16] studying the link between STAT3 and autophagy in H9c2 cells and rats, subjected to RIPreC and H/R and IR, respectively, found that RIPreC applied prior to IR reduced the IS and upregulated autophagy in heart tissue at $24 \mathrm{~h}$ post-RIPreC. Interestingly, they detected the activation of STAT3 and an increased plasma level IL-6 immediately after RIPreC, indicating that JAK/STAT3 signaling occurs upstream to autophagy upregulation. Besides, pretreatment with AG490 abolished RIPreC-induced autophagy upregulation in vitro. These results suggest STAT3-dependent autophagy activation as a putative mechanism for RIPreC cardioprotection. In another study with a similar model, the same group found that the RIPreC-induced increase in IL-6 plasma level and subsequent JAK-STAT pathway activation, was dependent on the early growth response-1 (Egr-1) transcription factor [17]. The silencing of Egr-1 led to a decrease in STAT3 Y705 phosphorylation and an increase in hypoxic damage in vitro and IS in vivo. Both these two studies highlight the importance of the increase of plasma IL-6 secretion after $\mathrm{RIPreC}$ to protect the heart against IRI. Yet, it has been proposed that IL- 6 can signal in cardiomyocytes independently of STAT $1 / 3$ and that the activation of ERK $1 / 2$ and PI3K by IL-6 is required for inducing cardioprotection. Consistently, IL-6 induces the activation of MAPKs and in particular of p38-MAPK, which acts as negative feedback regulator of JAK/STAT activation in cardiomyocytes [49]. Indeed, the inhibition of p38-MAPK enhances STAT3 phosphorylation. This suggests that a balance exists between MAPKs and JAK/STAT in cardiomyocyte survival.

An interesting study of Skyschally et al. [191] focused on RIPerC and its mechanism of protection in pigs, rats and mice. RIPerC in pigs exerted a cardioprotective effect, whose magnitude was similar to the one induced by RIPreC $[190,191]$. In both experiments, the conditioning maneuvers provided the same results in terms of protection by activating STAT3 but not RISK pathway in pig hearts, as indicated by low levels of Akt and ERK1/2 phosphorylation. The transfer of plasma from pigs who underwent either RIPerC or RIPreC, to isolated mice or rat hearts, protected these hearts from the ex vivo IR. Intriguingly, the transfer of humoral factors contained in the pig plasma, activated both RISK and SAFE pathways in rodent's hearts and both pathways were fundamental to reduce IS. In isolated rat cardiomyocytes, the transfer of pig plasma helped to preserve complex I mitochondrial respiration, improve mitochondrial ATP production and reduce ROS formation. These effects were abolished by the use of both RISK and SAFE pathway inhibitors. To investigate whether RIC induces the release of cardioprotective factors also in humans, Hildebrandt et al.
[82] harvested the plasma from healthy volunteers undergoing RIC from $5 \mathrm{~min}$ post procedure up to 6 days. The plasma was subsequently given to isolated mice hearts before the induction of IR and revealed to be protective and reduce IS up to $50 \%$. An increased STAT3 phosphorylation, but not Akt and ERK1/2, was detected in mice hearts treated with the RIC-plasma and the additional treatment with STAT3 inhibitor Stattic abrogated the cardioprotection. The above studies suggest that STAT3 is crucial in pigs and humans, whereas RISK is involved in rodents only. The different effects of humoral factors of animal or human plasma in rodent's hearts may be due to the inter-species transfer differences. In addition, the signal transduction may be different in healthy or diseased subjects, in which confounding factors are present (See also below "Effects of common risk factors and confounders on STAT3 cardioprotection").

Differently from the Hildebrandt et al. study [82], in which healthy volunteers were enrolled, in a recent clinical trial the effect of humoral factors of patients suffering acute coronary syndrome (ACS) has been evaluated [38]. In this study the role of STAT3 in inducing cardioprotection has been demonstrated. In particular, extracellular vesicles (EV) were collected from ACS patients without or with RIPreC before percutaneous coronary intervention (PCI) and tested in-vitro and an ex-vivo IR models [38]. EV recovered from non-preconditioned patients induced protection against IRI, both in vitro and in ex vivo model. Pre-treatment of the isolated rat heart with the specific STAT3 inhibitor, Stattic, supports the idea that STAT3 is crucial for EV-mediated protection. Moreover, in these EV silencing of dual-specificity phosphatase 6, a member of the MAPK phosphatase family, prevented STAT3 phosphorylation and cardioprotection in the rat heart. EV collected from patients subjected to RIPreC were found non-protective. "Hyperconditioning" [227] has been proposed for explaining the loss of EV-RIPreC-mediated cardio-protection in these ACS patients, already suffering from ischemic events.

Another interesting study [97] suggested that the protection provided by RIPerC may be mediated not only by STAT3 pathway activation, which occurs only hours after the ischemia, but also by a more immediate neuronal response in pigs. Indeed, during the coronary occlusion the authors observed an attenuated ST-segment elevation in the RIPerC group, which correlated with reduced IS and was related to neuronal stimuli rather than circulating factors. In addition, it was found that splenectomy abolished RIPreC cardioprotection and the RIPreC-induced STAT3 phosphorylation in pigs and in rats [133]. Besides, in rats only, the vagal nerve seems to have a mandatory role in the transduction of RIPerC cardioprotection.

Despite the majority of the preclinical studies confirming a causal role of STAT3 in the protective mechanism of RIC, other players may intervene and species-specific differences 
may have a relevant influence too. Indeed, clinical evidence demonstrated the involvement of STAT5 in humans. In patients undergoing coronary artery bypass grafting (CABG) surgery, RIPreC was able to lower the troponin I levels and protect the myocardium, but STAT5 was the only STAT protein whose phosphorylation was significantly increased after applying RIPreC [56, 80]. Accordingly, in STAT5 KO mice, it has been reported that the cardioprotective effects against myocardial IRI by RiPreC are abrogated [30]. In particular, in these hearts, STAT5 was found to be crucial for RIPreC-mediated IS reduction through the PI3K/AKT survival pathway and the anti-apoptotic cascade, thereby confirming the importance of RISK in rodents. Conversely, STAT3 was found activated/phosphorylated in STAT5 KO mice and was not further phosphorylated by RIPreC, revealing that when STAT5 is deleted, STAT3 is phosphorylated, but this activation is not sufficient to reprogram RIPreC cardioprotection against IRI. Yet, in isolated mouse hearts with cardiomyocyte STAT3 deletion, STAT5 significantly increased following ischemic challenging [59]. However, in this study, the authors analyzed the cardiac function only and found that the STAT5 activation by IPrec in this STAT3 KO model is insufficient to rescue the cardiac function. From these two studies $[30,59]$ we can speculate that STAT3 is more implicated in cardiac function, whereas STAT5 is fundamental against IRI in rodents.

Clinical trials demonstrated the effectiveness of RIPreC in attenuating cardiac IRI and improving the short-term prognosis. In the work of $\mathrm{Wu}$ et al. [230], the induction of RIPreC in children with a severe congenital cardiac disease (tetralogy of Fallot) prior to cardiopulmonary bypass surgery, was able to reduce the length of intensive care unit stay, as well as postoperative Troponin I and Creatinine Kinase-MB levels. Interestingly, in the RIPreC group, they observed higher expression of cardiac Hif-1a, p-Akt, p-STAT3 in Y705, p-STAT5, p-NOS and less mitochondrial swelling compared to the control group.

In other human studies, the involvement of STATs was questioned. For instance, in patients with coronary artery disease who underwent CABG, RIPreC applied before surgery was protective, as demonstrated by the lower Troponin I level [99]. Mitochondria isolated immediately after RIPreC showed increased ADP-stimulated complex I respiration, ATP production and $\mathrm{Ca}^{2+}$ retention capacity, as well as reduced ROS production; the contractile function of atrial trabeculae dissected before surgery and subjected to HR protocol, was significantly improved by a RIPreC maneuver. Despite this, the expression and phosphorylation of proteins including STAT3 were not different between the RIPreC group and the control group. However, in this study, protein phosphorylation was analyzed in human atrial trabeculae after in vitro HR at only 1-timepoint; therefore, it is possible that changes in protein phosphorylation were missed.
In summary, although a number of experimental studies relating to the parallels between STAT3 and STAT5 exist, to better clarify the role of these two proteins in human myocardial IRI more studies are needed. From the existing studies on humans $[18,56,80,230]$ and on animals [30, 59, 79], it appears that their roles in cardioprotection are largely species-specific. In some species/conditions STAT5 can replace STAT3 in a sort of Yin/Yang relationship, in others STAT5 appears as part of a completely different pathway.

Yet, some clinical studies [139, 152, 172] do not support the cardioprotective potential of RIPreC and this may be due to different factors, such as comorbidities of the patients as well as the choice of anesthetic during surgery (See also below "Effects of common risk factors and confounders on STAT3 cardioprotection").

\section{STAT3 in hypothermic conditioning}

Hypothermia is known to preserve cardiac function and prevent mitochondrial damage upon cardiac IRI [163]. It is currently used in clinics to improve survival in post cardiac arrest settings [161]. STAT3 seems to be involved in the mechanism of protection underlying the hypothermic conditioning [88]. Huang et al. [88] studied the mitochondria of rat hearts subjected to cardiac arrest and resuscitation with or without hypothermia $\left(32^{\circ} \mathrm{C}\right)$ and they observed less mitochondrial swelling and mPTPs opening in the hypothermic group and amelioration of complex I/III activity of the ETC. Interestingly, the amount of Y705 phosphorylation and STAT3 expression in mitochondria was increased in hypothermic rats. The causal involvement of STAT3 was confirmed in vitro by the use of STAT3 inhibitor, which resulted in the abrogation of hypothermia-induced protection in H9c2 cells. Due to the relevance of this approach in the clinic, more studies on the mechanisms are needed.

\section{STAT3 in pharmacological conditioning}

Cardioprotection can be achieved thanks to administration of drugs and molecules before or after a coronary occlusion, that are, respectively, pharmacological pre- and postconditioning, which can be induced either with exogenous or endogenous agents. Even low doses of TNFo, administered as preconditioning or postconditioning agent, confer cardioprotection by modulating ROS production and inactivating pro-apoptotic proteins, such as Bad [43, 116, 118]. Indeed, ROS may trigger TNF $\alpha$-induced cardioprotection and their scavenging inhibits STAT3 phosphorylation [116, 147]. There is evidence that JAK-STAT3 activation may be obtained by several other factors, such as bradykinin, opioids, ethanolamine, melatonin, resveratrol, erythropoietin, cannabinoid agonists, insulin and prostaglandins (for 
reviews see $[71,114,115])$. In addition, a link between HDL and STAT3 has been described [64].

Recently, as shown in rat hearts subjected to LAD ligation, morphine preconditioning induced an increase in pY705 STAT3 and phosphorylated JAK2 and a reduction in IS [45]. Upon STAT3 inhibition with Stattic, these effects are lost, but using cyclosporine A, the protection is restored, suggesting that the positive effect of morphine relies on the inhibition of mPTPs that occurs downstream of STAT3 activation. Another study [62] about morphine conditioning on LAD-ligated rat hearts, highlights that morphine-induced pY705 STAT3 and phosphorylated JAK2 are fundamental in the crosstalk with RISK pathway, which in turn leads to the regulation of GSK-3 $\beta$ and confers cardioprotection. Indeed, Akt and GSK-3 $\beta$ phosphorylations are abrogated in presence of AG490, the inhibitor of JAK2/STAT3, and at the same time, STAT3 phosphorylation was abolished in the presence of the Akt inhibitor, wortmannin. The same crosstalk was observed by Shravah et al. [187] on H9c2 cells treated with propofol, an intravenous anesthetic exerting anti-apoptotic effects on cardiomyocytes. Propofol treatment induced phosphorylation of STAT3 in Y705 and S727; both of them were detected for up to $30 \mathrm{~min}$, while at $6 \mathrm{~h}$ only Y705 phosphorylation was sustained. This finding correlates with the observation of nuclear translocation of STAT3 after $4 \mathrm{~h}$ of propofol treatment.

Evidence about STAT3 in mediating cardioprotection via the regulation of mitochondrial function is also provided by the work of Lemoine et al. [125]. They demonstrated that the administration of atorvastatin at early reperfusion prevents mPTPs opening and that this is dependent on STAT3 and TNF-alpha signaling in human atrial trabeculae model of $\mathrm{H} / \mathrm{R}$ injury. In particular, in human atrial trabeculae exposed to $\mathrm{H} / \mathrm{R}$, atorvastatin ameliorated the contractile force in comparison with H/R control and increased Y705 STAT3 and JAK2 phosphorylation. Atorvastatin lost its cardioprotective effect in presence of TNF $\alpha$ and STAT3 inhibitors, while the addition of cyclosporine A (mPTPs opening inhibitor) restored the protection. This indicates an involvement of the SAFE pathway in the protection by atorvastatin and places the inhibition of mPTPs opening downstream of the activation of TNF $\alpha$, JAK2, and STAT3.

Sodium-glucose cotransporter-2 inhibitors (SGLT2) are emerging as a class of anti-diabetic compounds exerting unexpected beneficial cardiovascular effects [6]. Among the SGLT2 inhibitors, different mechanisms of cardioprotection have been reported. For example, empagliflozin reduces IS by increasing STAT3 phosphorylation at early reperfusion in in vivo hearts of mouse fed weed western diet to induce diabetes [7]. Moreover, in healthy mice, chronic, but not acute, empagliflozin administration reduces IS via the STAT3 pathway [160]. Yet, another SGLT2 compound, dapagliflozin, attenuates cardiac fibrosis by regulating the macrophage polarization via STAT3 signaling in infarcted rat hearts [123]. Distinct mechanisms of cardioprotection could be speculated among the various SGT2 inhibitors.

Many endogenous compounds used in pharmacological conditioning induce STAT3 signaling. For example, the obesity-related adipokine leptin protects against IRI in various tissues including gut, kidney, brain and heart in which leptin activates both RISK and SAFE pathways [193]. Actually, the cardiac leptin signaling has been demonstrated to be fundamental to the cardiac structure and function after MI, by attenuating hypertrophy and metalloproteinase activity, reducing cardiomyocytes apoptosis and inflammation, maintaining the left ventricle contractility and preventing left ventricular dilation [148, 149]. In particular, Mcgaffin et al. [149] performed LAD ligation on cardiomyocyte-specific leptin-deficient mice and they found reduced cardiac function associated with the loss of STAT3 signaling and STAT3-responsive gene transcription. Smith et al. [193], using isolated rat hearts treated with leptin at the beginning of reperfusion, found a decrease in IS as well as early (2,5 min) STAT3 Y705 phosphorylation and subsequent (15 min) Akt phosphorylation. The addition of AG490 caused the loss of leptin-induced protection but did not affect Akt levels. In vitro, they observed that leptin postconditioning reduced mPTPs opening; this effect was abrogated in presence of AG490, indicating that STAT3 may be involved in mitochondrial regulation.

Another hormone, ghrelin, has been tested in the context of cardioprotection. Ghrelin is a 28 amino acid peptide initially isolated from the stomach, whose acylation is essential for binding to growth hormone (GH)-secretagogues-receptor type 1a and its endocrine functions. Although lacking GHS-R binding, unacylated ghrelin shares several effects with acylated ghrelin. Ghrelin exerts different activities on the cardiovascular system, such as modulation of cardiac contractility, inhibition of cardiac and endothelial cells apoptosis and improvement of left ventricular function in IR heart [168]. Treatment of rats with ghrelin for 3 weeks, after induction of MI, improved LV contraction, decreased expression of pro-apoptotic proteins, determined myocardial suppressor of cytokine signaling 3 (SOCS3) expression (an inhibitor of JAK2/STAT3 signaling) and STAT1 phosphorylation, improved antioxidant activity and increased JAK2 phosphorylation and STAT3 phosphorylation in both Y705 and S727 in a rat model of MI with LAD ligation [47]. According to these results, the protective effect of ghrelin may be mediated by the inhibition of JAK1/STAT1 signaling, which leads to pro-apoptotic effects, and by the inhibition of SOCS3. Using cardiac-specific SOCS3 KO mice, it has been shown that SOCS3 is key factor that exacerbates the myocardial IRI development [155]. 
In ex vivo (isolated rat hearts) model and in vitro (isolated mouse cardiomyocytes) model of IR, Fuglesteg et al. [53] demonstrated that insulin induces cardioprotection at reperfusion, by activating STAT3. Again, the inhibition of STAT3 through AG490, negatively affected the activation of Akt, suggesting a crosstalk between these two mediators.

We mentioned above the importance of S1P in STAT3 activation. Actually, S1P is a proinflammatory mediator of allergic diseases and exerts its functions through five specific cell surface receptors (S1PR1-5) [105, 141, 216]. However, $\mathrm{S} 1 \mathrm{P}$ is also a potent protectant against IRI [179, 214]. The $\mathrm{S} 1 \mathrm{P}$ cardioprotection is mediated by interaction with types 1, 2 and/or 3 S1PRs leading to the activation of RISK and/ or SAFE pathways $[37,150]$. Specifically, S1P treatment at early reperfusion protected isolated mice hearts subjected to IR by activating both RISK and SAFE pathways [197]. In this model, the decrease in IS was abolished both with the use of AG490 and STAT3 ${ }^{-1-}$ mice. Interestingly, they found a peculiar kinetic of STAT3 S727 phosphorylation in the different cell compartments: an increase in phosphorylation was found both in the nucleus and in the mitochondrial fraction at $7 \mathrm{~min}$ post-reperfusion, while it persisted at $15 \mathrm{~min}$ post-reperfusion only in the nucleus: STAT3 translocation to mitochondria may be related to its cardioprotective effect.

In conclusion, exogenous and endogenous compounds may induce pharmacological conditioning involving either RISK and/or SAFE pathways. Undoubtedly, further research is needed to delineate the main mechanisms involved in cardioprotection induced by these agents. Furthermore, the elucidation of the possible protective mechanisms of these factors on myocardium with or without comorbidities could increase the probability of success in terms of translating cardioprotection in the clinical setting for a real benefit of the patient. Since STAT3 is involved in a wide range of patho-physiological cardiac conditions, pharmacological activation or inhibition of STAT3 may be represent a therapeutic strategy to treat them.

\section{Some more considerations on mitochondrial STAT3 in IRI and cardioprotection}

As seen above, STAT3 is a major member of the well-known cardioprotective SAFE pathway that leads to the activation of several pro-survival signals contributing to protect cells against IRI. There is a number of studies [23, 53, 83, 147, $157,194]$ evidencing the essential role of STAT3 in cardioprotection against IRI, also through the use of STAT3 KO and pharmacological STAT3 inhibition. The KO of STAT3 and the inhibitors AG490 and Stattic are commonly used techniques to study the role of STAT3; these methods block all the functions of STAT3, without discriminating between transcriptional and mitochondrial function. Several studies showed that STAT3 is phosphorylated and activated in different timepoints of IR episode, but only few works have been done to distinguish and characterize the S727 and Y705 phosphorylation and their effects on STAT3 localization and function. A possible reason for this lack of insight can be due to the complexity of the model required to study separately STAT3 as a transcription factor and STAT3 as a mitochondrial effector, since no well-defined mechanism to distinguish them has been found yet. The different sites of phosphorylation, S727, and Y705, may represent a way to identify different activities of STAT3, but more studies should be done to verify if phosphorylation on S727 is specifically and univocally required for the mitochondrial action. Until now the S727 site seems to be important for some of the mitochondrial functions of STAT3, but it cannot be considered yet a specific marker to define mitochondrial STAT3. One interesting method that has been adopted by some research groups that wanted to focus only on mitochondrial STAT3 is the creation of MLS-STAT3, which is obtained by fusing the sequence of STAT3 with the mitochondrial targeting sequence of the subunit VIII of cytochrome $\mathrm{c}$. The main disadvantage of this technique is that it forces the expression of a non-physiological mitochondria-targeted STAT3, and as such it does not allow to study of what happens physiologically in myocardium. Heusch et al. [79] observed that the reduction in IS caused by IPostC in pig hearts was accompanied by a better mitochondrial function, with preservation of complex I and better $\mathrm{Ca}^{2+}$ retention capacity; interestingly, in mitochondria from post conditioned pig heart they found an increased phosphorylation of mitochondrial STAT3 at the Y705 site. Among the few researchers that investigated the role of mitochondrial STAT3 in the IRI model, Szczepanek et al. [205] used transgenic MLS-STAT3 mice; in MLS-STAT3 hearts they found a better response to IR in term of IS and contractile recovery, as well as reduction of ROS after reperfusion, in comparison with WT hearts [204, 206]. The same group studied how mitochondrial function in particular complex I respiration, was improved by STAT3 overexpression in mitochondria, suggesting that the protective mechanism mediated by STAT3 is independent of its activity as a transcription factor. Wang et al. [220] have demonstrated that the zinc transporter Zip2 regulates mitochondrial respiration via STAT3 phosphorylation during IR. In particular, in $\mathrm{Zip}^{-/-}$mice undergoing an in vivo LAD ligation, mitochondrial respiratory rates and oxidative phosphorylation are decreased together to the levels of S727-phosphorylated STAT3. The restoration of mitochondrial function occurred only upon the reintroduction of STAT3 expression, while STAT3 dominant negative mutant (STAT3 S727A) inhibited mitochondrial respiratory function, suggesting the importance of the S727 site for mitochondrial regulation. 
In cardiomyocyte STAT3 KO mice, Hilfiker-Kleiner et al. [83] observed increased mRNA levels of the proautophagy/pro-apoptotic protein BNIP3 $24 \mathrm{~h}$ after reperfusion, while mRNA levels of the prosurvival gene HSP70 were decreased. They described greater apoptosis and IS with impaired fractional shortening after 7 days. However, no changes were observed in VEGF and in the anti-oxidant protein SOD2.

Yet, STAT3 signaling, other than regulating many responses in cardiomyocytes, is also active in the endothelial cells, where it contributes to anti-inflammatory and anti-apoptotic response [251], angiotensin II-induced fibrosis [86], oxidative stress modulation [7], and vasodilation [224]. According to this, endothelial STAT3 may have an important role in the protection versus IRI; for example, in mouse model of IR, the ablation of endothelial STAT3 led to a decrease of cardiac function supported by increased inflammation and worsening of capillary integrity [221]. Other authors demonstrated that in hypoxic human coronary artery endothelial cells, the treatment with statin rosuvastatin improved cell survival through the JAK/STAT3 pathway [218].

\section{Effects of common risk factors and confounders on STAT3 cardioprotection}

Obviously, in AMI patients, it is possible to apply treatment only after the ischemia at early reperfusion, since the ischemic event cannot be predicted. As seen, pharmacological postconditioning at the early reperfusion phase promotes pro-survival and antioxidant mechanisms in the damaged cells and the treatment at late reperfusion appears to be less efficient [58]. Therefore, the studies about pharmacological postconditioning are the most relevant to clinical reality. As seen, STAT3 seems to have a protective role in various models of cardiac IR, even if different results about the timing and site of activation are present. Nevertheless, the results obtained in pre-clinical studies often do not correspond to the findings in clinical studies, suggesting that the speciesspecific differences in the responsiveness to treatment are strongly relevant. Yet, multiple factors including comorbidities and/or co-medications may influence the molecular environment in cardiac and non-cardiac tissues, determining the outcome in humans in the responses to RIC maneuvers $[50,98]$.

A known confounder of cardioprotection by RIC is the anesthesia. In this respect, STAT5 function may be relevant. As mentioned, it has been proposed that the SAFE pathway plays a more important role in larger mammals, where STAT5 is also important, making it particularly interesting from a translational viewpoint $[70,79,189,190]$. Indeed, STAT5 phosphorylation is not only associated with, but causally involved in cardioprotection as suggested by the clinical study of Kottenberg et al. [101]. In this study propofol interfered with STAT5 activation and consequently with RIPreC-mediated protection, suggesting an association between a lack of RIPreC effect and the lack of STAT5 activation. Nevertheless, RIC decreased troponin release and increased STAT5 phosphorylation in patients undergoing cardiac surgery under isoflurane [80]. Augmented STAT5 phosphorylation in the left ventricle was also observed during cardioprotection under sevoflurane anesthesia [230]. The difference may be due to intravenous anesthesia (propofol) or volatile anesthesia, as suggested by the network metaanalysis of randomized trials, which confirmed the interference of intravenous anesthesia with RIC in reducing postoperative mortality [242].

Actually, a multitude of risk factors influences the onset and prognosis of ischemic heart disease, altering endogenous cardiac signaling and possibly interfering with cardioprotective strategies, including IPreC and IPostC [50, 98]. Since confounding factors such as age, sex, diabetes, and hypertension/hypertrophy may alter the benefits provided by the activation of the RISK and SAFE pathway, here we consider possible effects that these unfavorable factors may have on cardiac STAT3. Again, the majority of the evidence about confounder's influence refers to STAT3 in the SAFE pathway, but a few studies can be linked specifically to the mitochondrial function of STAT3. Here, we consider some of these confounders and analyze the variations occurring on phosphorylation of S727 STAT3, the putative key step for STAT3 entry within mitochondria.

\section{Aging}

\section{Effects on the extent of IRI}

Aging enhances the extent of IRI in unprotected myocardium due to age-induced defects in mitochondrial function as shown by Lesnefsky and Hoppel group [126, 127]. This may be related to STAT3 inhibition. Indeed, in aging rat heart lower phosphorylation of total STAT3 in comparison with younger animals has been observed [29]. Furthermore, Wegrzyn et al. [225] demonstrated that in mice STAT3 null hearts, the activities of complex I and II are decreased, leading to a reduction in the oxidative phosphorylation system (OXPHOS) efficacy.

\section{Effects on cardioprotection}

Aging is known to reduce the protection associated with ischemic conditioning, and a possible explanation may be the impairment of mitochondrial function and TNF-stimulated signaling, such as the SAFE pathway [18, 20, 126]. In aged rodents IPostC applied at reperfusion resulted in less 
efficiency in reducing IS in comparison with younger mice, and the increased IS was associated with reduced phosphorylation of S727 STAT3 [18]. In particular, in young mice ( 3 months) both 3 cycles of $10 \mathrm{~s}$ of ischemia/10 s of reperfusion $(3 \times 10 \mathrm{~s})$ and 5 cycles of $5 \mathrm{~s}$ of ischemia/5 s of reperfusion $(5 \times 5 \mathrm{~s})$ reduced IS, whereas in aged mice (>13 months), only $5 \times 5 \mathrm{~s}$ was effective in reducing the infarct area. In young mice, $3 \times 10 \mathrm{~s}$ IPostC increased the phosphorylation of STAT3 in S727 at 10 min of reperfusion, whereas in aged mice hearts, phosphorylated STAT3 was reduced compared with young mice hearts. Other groups demonstrated that in the heart from old mice there is a lower expression of total STAT3. For example, Boengler et al. [20] reported a reduced STAT3 protein level in mitochondria isolated from cardiac tissue of aged mice compared to younger mice. Furthermore, in this study Boengler et al. [20] suggested the potential clinical relevance of STAT3 by highlighting that a reduced level of mitochondrial STAT3 in elderly hearts may be important for the loss of cardioprotection. Taken together, these studies highlighted the reduced STAT3 level in aged hearts with higher susceptibility to IR challenging and subsequent loss of cardioprotection.

\section{Diabetes}

\section{Effects on the extent of IRI}

In addition to harmful consequences of diabetes on the cardiovascular system, such as cardiopathy and vasculopathy, diabetes increases specifically the risk to develop ischemic heart disease [34, 167]. Interestingly, diabetes seems to alter cardiac STAT3 signaling, lowering its activation at the S727 site in both in vivo and in vitro models [217], even if in some other cases, increased activation of canonical STAT3 was observed in diabetic animals [203]. Of note, STAT3 is known to protect the heart from oxidative stress ant it is able to preserve the myocardium in postpartum cardiomyopathy in female mice [84]. Indeed, a specific cardiac deletion of STAT3 in KO females leads to this disease [84]. The involvement of STAT3 in either the activation of diabetic or antidiabetic mechanisms in the development of diabetic and postpartum cardiomyopathy has been summarized in a recent review [66]. Despite not all evidence being coherent, diabetes contributes to worsening IRI, most likely through induction of oxidative stress and consequent loss of cardioprotective strategies efficacy [165]. For example, reduced STAT3 5727 phosphorylation in diabetic rats has been linked to increased susceptibility to IRI, resulting in increased IS [131, 217].

\section{Effects on cardioprotection}

Lei et al. [124] demonstrated that pharmacological preconditioning with Remifentanil in rats increased phosphorylation of STAT3 at Y705 and reduced IS. These protective effects were abrogated in diabetic rats, in which STAT3 failed to be phosphorylated both at Y705 and S727 [124]. The study of Liu et al. [136] investigated the influence of diabetes on RIPreC maneuver on rats. In particular, in diabetic rats subjected to liver RIPreC, IS and apoptosis level were reduced to the same extent as in non-diabetic rats. Interestingly, the cardioprotection of liver RIPreC in diabetic rats appeared to rely on GSK-3 $\beta /$ STAT5 signaling, since STAT5 activation and not STAT3 was detected in these hearts. Therefore, not all the evidence converges towards a single conclusion, but this can be due to the fact that diabetes can modulate the cardiac environment towards a less or more protective one in the different phases of its pathophysiology [167].

\section{Cardiac hypertrophy}

Several studies highlighted that the inhibition of STAT3 induces downregulation of synthesis of collagen and subsequently regression of hypertrophy. Moreover, overexpression of STAT3 in murine cardiomyocytes leads to cardiac hypertrophy by increasing expression of hypertrophic genes, such as atrial natriuretic factor (ANF) $[66,106]$. Regarding STAT3's role in mitochondrial regulation of cardiac hypertrophy, it protects mitochondria indirectly via upregulation of the anti-apoptotic proteins, such as Bcl2. In addition, STAT3 preserves mitochondrial integrity and inhibits ROS generation via its interaction with CypD and inhibition of the opening of the mPTPs [78, 87, 151]. Finally, Chen et al. [31] investigated whether angiotensin II-induced cardiomyocyte hypertrophy is affected by STAT3-mediated inhibition of cellular autophagy on H9c2. They reported that STAT3 modulates autophagy to balance the transcriptional hypertrophic response to angiotensin II stimulation.

Under stressful conditions, high levels of catecholamine are associated with several types of cardiac dysfunction, such as arrhythmias, coronary spasm, $\mathrm{Ca}^{2+}$ abnormalities in sarcolemma and sarcoplasmic reticulum, deficiency in mitochondrial energy production and myocardial cell damage, as well as cardiac hypertrophy [2, 90, 93]. Several factors have been proposed as promoters of hypertrophy [208]; among them, STAT3 was examined by Jeong et al. [93] in an in vitro model of catecholamine-induced hypertrophy. In this model they observed an impaired oxidative phosphorylation in mitochondria, as demonstrated by the downregulation of mitochondrial complexes II and III. In particular, they attributed a regulatory role to STAT3 phosphorylation at both Y705 and S727 sites in these hypertrophic H9c2 cells 
exposed to catecholamines. While the expression and activation of pY705-STAT3 in the nucleus were increased leading to the transactivation of hypertrophic responsible genes, such as ANF and c-fos, the pS727-STAT3 phosphorylation in mitochondria was attenuated. Moreover, the oxidative phosphorylation system of mitochondria was significantly downregulated, likely through the reduction of pS727STAT3 activation.

Moreover, Stapel et al. [199] emphasize the critical implication of STAT3 in the sensitivity of $\beta$-adrenergic receptor (BAR) toxicity. They observed reprogrammed cardiomyocyte oxygen metabolism upon $\beta$-adrenergic stimulation in STAT3 KO mice, in particular an increased ADP/ATP ratio and lower $\mathrm{O}_{2}$ consumption.

In an effort to identify the potential involvement of STAT3 in $\beta$-adrenergic signaling Zhang et al. [246] studied BAR-mediated STAT3 activation, using conditional STAT3 KO (STAT3cKO) mice hearts. STAT3 should be involved in the regulation of BAR signaling via cAMP. In particular, in STAT3cKO hearts upon BAR stimulation cAMP level were downregulated and this was associated with lower left ventricular contractile and relaxation properties. This evidence was supported by the results obtained in the in vitro cardiomyocyte STAT3cKO model, where they found reduced anti-apoptotic proteins, indicating the activation of apoptotic processes.

Overall, these experimental studies suggest that a modulation of STAT3 plays a central role in the development of hypertrophy and may represent a new therapeutic strategy to treat cardiac hypertrophy. Whether these effects contribute to IRI exacerbation and loss of cardioprotection remains to be ascertained.

\section{Effects on the extent of IRI}

Several cardiovascular pathologies as well as hypertension can cause maladaptive hypertrophy of cardiac myocytes in response to an increased workload. When hypertrophy develops, IRI are exacerbated and cardioprotection is compromised; for Review see [165]. Moreover, Enomoto et al. [48] demonstrated that cardiac-specific ablation of the STAT3 gene exacerbated post-infarct cardiac remodeling. In particular, in STAT3 null mice, reduced capillary density was detected compared to control mice after myocardial infarction, suggesting that cardiac specific ablation of the STAT3 gene leads to severe hypertrophy without coordination with capillary growth. Overall, STAT3 downregulation by hypertrophic pathological conditions can exacerbates IRI, and STAT3 intrinsic activity is required for the prevention of maladaptive cardiac remodeling in the subacute phase of myocardial infarction.

\section{Effects on cardioprotection}

On the other hand, STAT3 downregulation by hypertrophic pathological conditions can also lead to the loss of efficacy of cardioprotective maneuvers, such as RIC [165]. In a clinical study, Sloth et al. [192] observed in 139 patients with STEMI and left ventricular hypertrophy that the RIPreC effect tended to be attenuated, even if no statistic differences were reached neither for patients with hypertrophy nor with hypertension. In the work of Song et al. [198], RIPreC was ineffective in inducing the activation of cardioprotective pathways (RISK and SAFE) when applied before aortic valve replacement in patients suffering from aortic stenosis, who are characterized by concentric left ventricular hypertrophy. CK-MB and troponin I levels were not affected by the RIPreC, as well as no changes in RISK pathway elements nor in STAT3 phosphorylation were detected. STAT5 phosphorylation was decreased in the RIPreC group, and caspase 3 was upregulated, suggesting that some cellular damage has occurred. These results lead to the conclusion that the presence of a hypertrophic phenotype influences the outcome of RIPreC maneuver, but the reason remains unclear. A possible explanation for lack of activation of the RISK pathway can be that in myocardium with chronic hypertrophy, a persistent activation of Akt exists [145], which might be linked to a feedback inhibition of upstream RISK pathway.

Overall, in several cardiac responses observed in hypertrophic hearts, such as stress adaptation, pathological remodeling, heart failure, IRI and cardioprotection modifications, STAT3 shows a fundamental function as a critical transcription factor and/or a modulator of mitochondrial function.

\section{Conclusion}

Overall, in this review, we highlight the role of STAT3 as a protein with non-genomic functions. Initially, the research focused on the genomic functions of STAT3, as a transcription factor, but then it became clear that it has a fundamental role in the mitochondria and in the non-genomic network [e.g., 20, 210, 225], opening the horizon towards the understanding of the pro-survival functions of this protein.

In cardioprotection scenario, STAT3, by regulating mitochondrial $\mathrm{Ca}^{2+}$ and ROS homeostasis and preventing mPTPs opening, contributes to the recovery of mitochondrial function following IR episode, which is a fundamental prerequisite in the mechanism of efficient cardiac conditioning.

Although the most recent data suggest that optimal cardioprotection can be reached with the combination of additive or synergistic multitarget therapies [39], understanding how to preserve the $\Delta \Psi \mathrm{m}$ and maintain the proton motive force by preserving the normal function of the F1F0-ATPase 
pump would undoubtedly result in an improvement in the response to IR. The available data on STAT3 in mitochondria and its influence on mitochondrial function represent a basis for further studies addressing the exact contribution of the role of mitochondrial proteins in cardioprotection.

Here we have discussed some recent studies that highlight the key role of STAT3 in cardioprotection, which, together with other regulatory (e.g., STAT5) and pathways, plays a central role also in humans and in experimental models relevant for translation from bench research to clinic [e.g., 79, $80,98,100,101,191]$.

We hope that the results reported in this review will encourage more and more researchers to deepen their studies and clarify the remaining doubts about STAT3 pro-survival role in the cardiovascular field. In particular, the function exerted on the ETC to maintain its efficiency and prevent ROS formation represents an excellent starting point to justify the interest in understanding the mechanisms underlying this role of STAT3 within mitochondria.

Author contributions SC, CT and SF wrote the first draft of the manuscript. GA, KB, PP and $\mathrm{CP}$ revised the manuscript critically for important intellectual content. All authors revised the manuscript. All authors have read and agreed to the published version of the manuscript.

Funding Open access funding provided by Università degli Studi di Torino within the CRUI-CARE Agreement.

Open Access This article is licensed under a Creative Commons Attribution 4.0 International License, which permits use, sharing, adaptation, distribution and reproduction in any medium or format, as long as you give appropriate credit to the original author(s) and the source, provide a link to the Creative Commons licence, and indicate if changes were made. The images or other third party material in this article are included in the article's Creative Commons licence, unless indicated otherwise in a credit line to the material. If material is not included in the article's Creative Commons licence and your intended use is not permitted by statutory regulation or exceeds the permitted use, you will need to obtain permission directly from the copyright holder. To view a copy of this licence, visit http://creativecommons.org/licenses/by/4.0/.

\section{References}

1. Abid H, Ryan ZC, Delmotte P, Sieck GC, Lanza IR (2020) Extramyocellular interleukin-6 influences skeletal muscle mitochondrial physiology through canonical JAK/STAT signaling pathways. FASEB J 34:14458-14472. https://doi.org/10.1096/ fj.202000965RR

2. Adameova A, Abdellatif Y, Dhalla NS (2009) Role of the excessive amounts of circulating catecholamines and glucocorticoids in stress-induced heart disease. Can J Physiol Pharmacol 87:493514. https://doi.org/10.1139/y09-042

3. Aggarwal BB, Kunnumakkara AB, Harikumar KB, Gupta SR, Tharakan ST, Koca C, Dey S, Sung B (2009) Signal transducer and activator of transcription-3, inflammation, and cancer: how intimate is the relationship? Ann N Y Acad Sci 1171:59-76. https://doi.org/10.1111/j.1749-6632.2009.04911.x
4. Alloatti G, Arnoletti E, Bassino E, Penna C, Perrelli MG, Ghé C, Muccioli G (2010) Obestatin affords cardioprotection to the ischemic-reperfused isolated rat heart and inhibits apoptosis in cultures of similarly stressed cardiomyocytes. Am J Physiol Heart Circ Physiol 299:H470-H481. https://doi.org/10.1152/ ajpheart.00800.2009

5. Alvarez SE, Harikumar KB, Hait NC, Allegood J, Strub GM, Kim EY, Maceyka M, Jiang H, Luo C, Kordula T, Milstien S, Spiegel S (2010) Sphingosine-1-phosphate is a missing cofactor for the E3 ubiquitin ligase TRAF2. Nature 465:1084-1088. https://doi.org/10.1038/nature09128

6. Andreadou I, Bell RM, Bøtker HE, Zuurbier CJ (2020) SGLT2 inhibitors reduce infarct size in reperfused ischemic heart and improve cardiac function during ischemic episodes in preclinical models. Biochim Biophys Acta Mol Basis Dis 1866:165770. https://doi.org/10.1016/j.bbadis.2020.165770

7. Andreadou I, Efentakis P, Balafas E, Togliatto G, Davos CH, Varela A, Dimitriou CA, Nikolaou P-E, Maratou E, Lambadiari V, Ikonomidis I, Kostomitsopoulos N, Brizzi MF, Dimitriadis G, Iliodromitis EK (2017) Empagliflozin limits myocardial infarction in vivo and cell death in vitro: role of stat3, mitochondria, and redox aspects. Front Physiol 8:1077. https://doi.org/10.3389/ fphys.2017.01077

8. Avalle L, Camporeale A, Camperi A, Poli V (2017) STAT3 in cancer: a double edged sword. Cytokine 98:42-50. https://doi. org/10.1016/j.cyto.2017.03.018

9. Avalle L, Camporeale A, Morciano G, Caroccia N, Ghetti E, Orecchia V, Viavattene D, Giorgi C, Pinton P, Poli V (2019) STAT3 localizes to the ER, acting as a gatekeeper for ERmitochondrion $\mathrm{Ca}^{2+}$ fluxes and apoptotic responses. Cell Death Differ 26:932-942. https://doi.org/10.1038/s41418-018-0171-y

10. Avalle L, Poli V (2018) Nucleus, mitochondrion, or reticulum? STAT3 à la carte. Int J Mol Sci 19:2820. https://doi.org/10. 3390/ijms 19092820

11. Aznar S, Valerón PF, del Rincon SV, Pérez LF, Perona R, Lacal JC (2001) Simultaneous tyrosine and serine phosphorylation of STAT3 transcription factor is involved in Rho A GTPase oncogenic transformation. Mol Biol Cell 12:3282-3294. https://doi. org/10.1091/mbc.12.10.3282

12. Barry SP, Townsend PA, Latchman DS, Stephanou A (2007) Role of the JAK-STAT pathway in myocardial injury. Trends Mol Med 13:82-89. https://doi.org/10.1016/j.molmed.2006.12. 002

13. Becker S, Groner B, Müller CW (1998) Three-dimensional structure of the Stat3beta homodimer bound to DNA. Nature 394:145-151. https://doi.org/10.1038/28101

14. Bernardi P, Rasola A, Forte M, Lippe G (2015) The mitochondrial permeability transition pore: channel formation by f-ATP synthase, integration in signal transduction, and role in pathophysiology. Physiol Rev 95:1111-1155. https://doi.org/10.1152/ physrev.00001.2015

15. Bernier M, Paul RK, Martin-Montalvo A, Scheibye-Knudsen M, Song S, He H-J, Armour SM, Hubbard BP, Bohr VA, Wang L, Zong Y, Sinclair DA, de Cabo R (2011) Negative regulation of STAT3 protein-mediated cellular respiration by SIRT1 protein. J Biol Chem 286:19270-19279. https://doi.org/10.1074/jbc.M110. 200311

16. Billah M, Ridiandries A, Allahwala UK, Mudaliar H, Dona A, Hunyor S, Khachigian LM, Bhindi R (2020) Remote ischemic preconditioning induces cardioprotective autophagy and signals through the IL-6-dependent jak-stat pathway. Int J Mol 21:1692. https://doi.org/10.3390/ijms21051692

17. Billah M, Ridiandries A, Rayner BS, Allahwala UK, Dona A, Khachigian LM, Bhindi R (2020) Egr-1 functions as a master switch regulator of remote ischemic preconditioning-induced 
cardioprotection. Basic Res Cardiol 115:3. https://doi.org/10. 1007/s00395-019-0763-9

18. Boengler K, Buechert A, Heinen Y, Roeskes C, Hilfiker-Kleiner D, Heusch G, Schulz R (2008) Cardioprotection by ischemic postconditioning is lost in aged and STAT3-deficient mice. Circ Res 102:131-135. https://doi.org/10.1161/CIRCRESAHA.107. 164699

19. Boengler K, Hilfiker-Kleiner D, Drexler H, Heusch G, Schulz R (2008) The myocardial JAK/STAT pathway: from protection to failure. Pharmacol Ther 120:172-185. https://doi.org/10.1016/j. pharmthera.2008.08.002

20. Boengler K, Hilfiker-Kleiner D, Heusch G, Schulz R (2010) Inhibition of permeability transition pore opening by mitochondrial STAT3 and its role in myocardial ischemia/reperfusion. Basic Res Cardiol 105:771-785. https://doi.org/10.1007/ s00395-010-0124-1

21. Boengler K, Ungefug E, Heusch G, Schulz R (2013) The STAT3 inhibitor stattic impairs cardiomyocyte mitochondrial function through increased reactive oxygen species formation. Curr Pharm Des 19:6890-6895. https://doi.org/10.2174/138161281939131 127115940

22. Bolli R, Dawn B, Xuan Y-T (2003) Role of the JAK-STAT pathway in protection against myocardial ischemia/reperfusion injury. Trends Cardiovasc Med 13:72-79. https://doi.org/10. 1016/S1050-1738(02)00230-X

23. Bolli R, Stein AB, Guo Y, Wang O-L, Rokosh G, Dawn B, Molkentin JD, Sanganalmath SK, Zhu Y, Xuan Y-T (2011) A murine model of inducible, cardiac-specific deletion of STAT3: its use to determine the role of STAT3 in the upregulation of cardioprotective proteins by ischemic preconditioning. J Mol Cell Cardiol 50:589-597. https://doi.org/10.1016/j.yjmcc. 2011.01.002

24. Burchfield JS, Dong J-W, Sakata Y, Gao F, Tzeng H-P, Topkara VK, Entman ML, Sivasubramanian N, Mann DL (2010) The cytoprotective effects of tumor necrosis factor are conveyed through tumor necrosis factor receptor-associated factor 2 in the heart. Circ Heart Fail 3:157-164. https://doi.org/10.1161/ CIRCHEARTFAILURE.109.899732

25. Cadenas S (2018) ROS and redox signaling in myocardial ischemia-reperfusion injury and cardioprotection. Free Radic Biol Med 117:76-89. https://doi.org/10.1016/j.freeradbiomed. 2018.01.024

26. Cai W-F, Kang K, Huang W, Liang J-L, Feng Y-L, Liu G-S, Chang D-H, Wen Z-L, Paul C, Xu M, Millard RW, Wang Y (2015) CXCR4 attenuates cardiomyocytes mitochondrial dysfunction to resist ischaemia-reperfusion injury. J Cell Mol Med 19:1825-1835. https://doi.org/10.1111/jcmm.12554

27. Cai ZP, Parajuli N, Zheng X, Becker L (2012) Remote ischemic preconditioning confers late protection against myocardial ischemia-reperfusion injury in mice by upregulating interleukin-10. Basic Res Cardiol 107:277. https://doi.org/10.1007/ s00395-012-0277-1

28. Canals D, Perry DM, Jenkins RW, Hannun YA (2011) Drug targeting of sphingolipid metabolism: sphingomyelinases and ceramidases. Br J Pharmacol 163:694-712. https://doi.org/10. 1111/j.1476-5381.2011.01279.x

29. Castello L, Maina M, Testa G, Cavallini G, Biasi F, Donati A, Leonarduzzi G, Bergamini E, Poli G, Chiarpotto E (2011) Alternate-day fasting reverses the age-associated hypertrophy phenotype in rat heart by influencing the ERK and PI3K signaling pathways. Mech Ageing Dev 132:305-314. https://doi.org/ 10.1016/j.mad.2011.06.006

30. Chen H, Jing XY, Shen YJ, Wang TL, Ou C, Lu SF, Cai Y, Li Q, Chen X, Ding YJ, Yu XC, Zhu BM (2018) Stat5-dependent cardioprotection in late remote ischaemia preconditioning.
Cardiovasc Res 114:679-689. https://doi.org/10.1093/cvr/ cvy014

31. Chen L, Zhao L, Samanta A, Mahmoudi SM, Buehler T, Cantilena A, Vincent RJ, Girgis M, Breeden J, Asante S, Xuan YT, Dawn B (2017) STAT3 balances myocyte hypertrophy vis-àvis autophagy in response to Angiotensin II by modulating the AMPK $\alpha / m$ TOR axis. PLoS ONE 12:e0179835. https://doi.org/ 10.1371/journal.pone. 0179835

32. Chernorudskiy AL, Zito E (2017) Regulation of calcium homeostasis by ER Redox: a close-up of the ER/mitochondria connection. J Mol Biol 429:620-632. https://doi.org/10.1016/j.jmb. 2017.01.017

33. Cheung CX, Healy DA, Walsh SR (2016) Remote preconditioning and cardiac surgery: regrouping after remote ischemic preconditioning for heart surgery (RIPHeart) and effect of remote ischemic preconditioning on clinical outcomes in patients undergoing coronary artery bypass surgery (ERICCA). J Thorac Dis 8:197-199. https://doi.org/10.21037/jtd.2016.01.81

34. Chiha M, Njeim M, Chedrawy EG (2012) Diabetes and coronary heart disease: a risk factor for the global epidemic. Int J Hypertens. https://doi.org/10.1155/2012/697240

35. Cho KH, Choi MJ, Jeong KJ, Kim JJ, Hwang MH, Shin SC, Park CG, Lee HY (2014) A ROS/STAT3/HIF-1 $\alpha$ signaling cascade mediates EGF-induced TWIST1 expression and prostate cancer cell invasion. Prostate 74:528-536. https://doi.org/10.1002/pros. 22776

36. Chung J, Uchida E, Grammer TC, Blenis J (1997) STAT3 serine phosphorylation by ERK-dependent and -independent pathways negatively modulates its tyrosine phosphorylation. Mol Cell Biol 17:6508-6516. https://doi.org/10.1128/mcb.17.11.6508

37. Cohen MV, Yang X-M, White J, Yellon DM, Bell RM, Downey JM (2016) Cangrelor-mediated cardioprotection requires platelets and sphingosine phosphorylation. Cardiovasc Drugs Ther 30:229-232. https://doi.org/10.1007/s10557-015-6633-2

38. D'Ascenzo F, Femminò S, Ravera F, Angelini F, Caccioppo A, Franchin L, Grosso A, Comità S, Cavallari C, Penna C, De Ferrari GM, Camussi G, Pagliaro P, Brizzi MF (2021) Extracellular vesicles from patients with acute coronary syndrome impact on ischemia-reperfusion injury. Pharmacol Res 170:105715. https:// doi.org/10.1016/j.phrs.2021.105715

39. Davidson SM, Ferdinandy P, Andreadou I, Bøtker HE, Heusch G, Ibáñez B, Ovize M, Schulz R, Yellon DM, Hausenloy DJ, GarciaDorado D, CARDIOPROTECTION COST Action (CA16225) (2019) Multitarget strategies to reduce myocardial ischemia/ reperfusion injury: JACC review topic of the week. J Am Coll Cardiol 73:89-99. https://doi.org/10.1016/j.jacc.2018.09.086

40. Dawn B, Guo Y, Rezazadeh A, Wang O-L, Stein AB, Hunt G, Varma J, Xuan Y-T, Wu W-J, Tan W, Zhu X, Bolli R (2004) Tumor necrosis factor-alpha does not modulate ischemia/reperfusion injury in naïve myocardium but is essential for the development of late preconditioning. J Mol Cell Cardiol 37:51-61. https://doi.org/10.1016/j.yjmcc.2004.03.012

41. Debnath B, Xu S, Neamati N (2012) Small molecule inhibitors of signal transducer and activator of transcription 3 (Stat3) protein. J Med Chem 55:6645-6668. https://doi.org/10.1021/jm300207s

42. Deshwal S, Di Sante M, Di Lisa F, Kaludercic N (2017) Emerging role of monoamine oxidase as a therapeutic target for cardiovascular disease. Curr Opin Pharmacol 33:64-69. https://doi.org/ 10.1016/j.coph.2017.04.003

43. Deuchar GA, Opie LH, Lecour S (2007) TNFalpha is required to confer protection in an in vivo model of classical ischaemic preconditioning. Life Sci 80:1686-1691. https://doi.org/10.1016/j. lfs.2007.01.040

44. Domoszlai T, Martincuks A, Fahrenkamp D, de Leur HS-V, Küster A, Müller-Newen G (2014) Consequences of the 
disease-related L78R mutation for dimerization and activity of STAT3. J Cell Sci 127:1899-1910. https://doi.org/10.1242/jcs. 137422

45. Dorsch M, Behmenburg F, Raible M, Blase D, Grievink H, Hollmann MW, Heinen A, Huhn R (2016) Morphine-induced preconditioning: involvement of protein kinase a and mitochondrial permeability transition pore. PLoS ONE 11:e0151025. https:// doi.org/10.1371/journal.pone.0151025

46. Drenger B, Ostrovsky I, Barak M, Nechemia-Arbely Y, Ziv E, Axelrod J (2011) Diabetes blockade of sevoflurane postconditioning is not restored by insulin in the rat heart. Anesthesiology 114:1364-1372. https://doi.org/10.1097/ALN.0b013e31820efafd

47. Eid RA, Alkhateeb MA, Eleawa S, Al-Hashem FH, Al-Shraim M, El-Kott AF, Zaki MSA, Dallak MA, Aldera H (2018) Cardioprotective effect of ghrelin against myocardial infarction-induced left ventricular injury via inhibition of SOCS3 and activation of JAK2/STAT3 signaling. Basic Res Cardiol 113:13. https://doi. org/10.1007/s00395-018-0671-4

48. Enomoto D, Obana M, Miyawaki A, Maeda M, Nakayama H, Fujio Y (2015) Cardiac-specific ablation of the STAT3 gene in the subacute phase of myocardial infarction exacerbated cardiac remodeling. Am J Physiol Heart Circ Physiol 309:H471-480. https://doi.org/10.1152/ajpheart.00730.2014

49. Fahmi A, Smart N, Punn A, Jabr R, Marber M, Heads R (2013) p42/p44-MAPK and PI3K are sufficient for IL-6 family cytokines/gp130 to signal to hypertrophy and survival in cardiomyocytes in the absence of JAK/STAT activation. Cell Signal 25:898-909. https://doi.org/10.1016/j.cellsig.2012.12.008

50. Ferdinandy P, Hausenloy DJ, Heusch G, Baxter GF, Schulz R (2014) Interaction of risk factors, comorbidities, and comedications with ischemia/reperfusion injury and cardioprotection by preconditioning, postconditioning, and remote conditioning. Pharmacol Rev 66:1142-1174. https://doi.org/10.1124/pr.113. 008300

51. Finkel T, Menazza S, Holmström KM, Parks RJ, Liu J, Sun J, Liu J, Pan X, Murphy E (2015) The ins and outs of mitochondrial calcium. Circ Res 116:1810-1819. https://doi.org/10.1161/ CIRCRESAHA.116.305484

52. Frias MA, Lecour S, James RW, Pedretti S (2012) High density lipoprotein/sphingosine-1-phosphate-induced cardioprotection: role of STAT3 as part of the SAFE pathway. JAKSTAT 1:92100. https://doi.org/10.4161/jkst.19754

53. Fuglesteg BN, Suleman N, Tiron C, Kanhema T, Lacerda L, Andreasen TV, Sack MN, Jonassen AK, Mjøs OD, Opie LH, Lecour S (2008) Signal transducer and activator of transcription 3 is involved in the cardioprotective signalling pathway activated by insulin therapy at reperfusion. Basic Res Cardiol 103:444453. https://doi.org/10.1007/s00395-008-0728-X

54. Gao S, Zhan L, Yang Z, Shi R, Li H, Xia Z, Yuan S, Wu Q, Wang T, Yao S (2017) Remote limb ischaemic postconditioning protects against myocardial ischaemia/reperfusion injury in mice: activation of JAK/STAT3-mediated Nrf2-antioxidant signalling. Cell Physiol Biochem 43:1140-1151. https://doi.org/10.1159/ 000481755

55. Garlid KD, Costa ADT, Quinlan CL, Pierre SV, Dos Santos P (2009) Cardioprotective signaling to mitochondria. J Mol Cell Cardiol 46:858-866. https://doi.org/10.1016/j.yjmcc.2008.11. 019

56. Gedik N, Thielmann M, Kottenberg E, Peters J, Jakob H, Heusch G, Kleinbongard P (2014) No evidence for activated autophagy in left ventricular myocardium at early reperfusion with protection by remote ischemic preconditioning in patients undergoing coronary artery bypass grafting. PLoS ONE 9:e96567. https:// doi.org/10.1371/journal.pone.0096567
57. Gent S, Skyschally A, Kleinbongard P, Heusch G (2017) lschemic preconditioning in pigs: a causal role for signal transducer and activator of transcription 3. Am J Physiol Heart Circ Physiol 312:H478-H484. https://doi.org/10.1152/ajpheart.00749. 2016

58. Gersh BJ, Stone GW, White HD, Holmes DR (2005) Pharmacological facilitation of primary percutaneous coronary intervention for acute myocardial infarctionis the slope of the curve the shape of the future? JAMA 293:979-986. https://doi.org/10. 1001/jama.293.8.979

59. Goodman MD, Koch SE, Afzal MR, Butler KL (2011) STAT subtype specificity and ischemic preconditioning in mice: is STAT-3 enough? Am J Physiol Heart Circ Physiol 300:H522526. https://doi.org/10.1152/ajpheart.00231.2010

60. Gorissen M, de Vrieze E, Flik G, Huising MO (2011) STAT genes display differential evolutionary rates that correlate with their roles in the endocrine and immune system. J Endocrinol 209:175-184. https://doi.org/10.1530/JOE-11-0033

61. Gough DJ, Corlett A, Schlessinger K, Wegrzyn J, Larner AC, Levy DE (2009) Mitochondrial STAT3 supports Ras-dependent oncogenic transformation. Science 324:1713-1716. https://doi. org/10.1126/science.1171721

62. Gross ER, Hsu AK, Gross GJ (2006) The JAK/STAT pathway is essential for opioid-induced cardioprotection: JAK2 as a mediator of STAT3, Akt, and GSK-3 beta. Am J Physiol Heart Circ Physiol 291:H827-H834. https://doi.org/10.1152/ajpheart.00003. 2006

63. Guo D, Dunbar JD, Yang CH, Pfeffer LM, Donner DB (1998) Induction of Jak/STAT signaling by activation of the type 1 TNF receptor. J Immunol 160:2742-2750

64. Hadebe N, Cour M, Lecour S (2018) The SAFE pathway for cardioprotection: is this a promising target? Basic Res Cardiol 113:9. https://doi.org/10.1007/s00395-018-0670-5

65. Harhous Z, Badawi S, Bona NG, Pillot B, Augeul L, Paillard M, Booz GW, Canet-Soulas E, Ovize M, Kurdi M, Bidaux G (2019) Critical appraisal of STAT3 pattern in adult cardiomyocytes. J Mol Cell Cardiol 131:91-100. https://doi.org/10.1016/j.yjmcc. 2019.04.021

66. Harhous Z, Booz GW, Ovize M, Bidaux G, Kurdi M (2019) An update on the multifaceted roles of STAT3 in the heart. Front Cardiovasc Med 6:150. https://doi.org/10.3389/fcvm.2019.00150

67. Hassinen IE, Vuorinen KH, Ylitalo K, Ala-Rämi A (1998) Role of cellular energetics in ischemia-reperfusion and ischemic preconditioning of myocardium. Mol Cell Biochem 184:393-400. https://doi.org/10.1023/A:1006818708565

68. Hausenloy D, Wynne A, Duchen M, Yellon D (2004) Transient mitochondrial permeability transition pore opening mediates preconditioning-induced protection. Circulation 109:1714-1717. https://doi.org/10.1161/01.CIR.0000126294.81407.7D

69. Hausenloy DJ, Barrabes JA, B $\varnothing$ tker HE, Davidson SM, Di Lisa F, Downey J, Engstrom T, Ferdinandy P, Carbrera-Fuentes HA, Heusch G, Ibanez B, Iliodromitis EK, Inserte J, Jennings R, Kalia N, Kharbanda R, Lecour S, Marber M, Miura T, Ovize M, PerezPinzon MA, Piper HM, Przyklenk K, Schmidt MR, Redington A, Ruiz-Meana M, Vilahur G, Vinten-Johansen J, Yellon DM, Garcia-Dorado D (2016) Ischaemic conditioning and targeting reperfusion injury: a 30 year voyage of discovery. Basic Res Cardiol 111:70. https://doi.org/10.1007/s00395-016-0588-8

70. Hausenloy DJ, Iliodromitis EK, Andreadou I, Papalois A, Gritsopoulos G, Anastasiou-Nana M, Kremastinos DT, Yellon DM (2012) Investigating the signal transduction pathways underlying remote ischemic conditioning in the porcine heart. Cardiovasc Drugs Ther 26:87-93. https://doi.org/10.1007/ s10557-011-6364-y 
71. Hausenloy DJ, Lecour S, Yellon DM (2011) Reperfusion injury salvage kinase and survivor activating factor enhancement prosurvival signaling pathways in ischemic postconditioning: two sides of the same coin. Antioxid Redox Signal 14:893-907. https://doi.org/10.1089/ars.2010.3360

72. Hausenloy DJ, Tsang A, Mocanu MM, Yellon DM (2005) Ischemic preconditioning protects by activating prosurvival kinases at reperfusion. Am J Phys Heart Circ Phys 288:H971H976. https://doi.org/10.1152/ajpheart.00374.2004

73. Hausenloy DJ, Yellon DM (2010) The second window of preconditioning (SWOP) Where are we now? Cardiovasc Drugs Ther 24:235-254. https://doi.org/10.1007/s10557-010-6237-9

74. Hausenloy DJ, Yellon DM (2013) Myocardial ischemia-reperfusion injury: a neglected therapeutic target. J Clin Invest 123:92100. https://doi.org/10.1172/JCI62874

75. Hausenloy DJ, Yellon DM, Mani-Babu S, Duchen MR (2004) Preconditioning protects by inhibiting the mitochondrial permeability transition. Am J Phys Heart Circ Phys 287:H841-H849. https://doi.org/10.1152/ajpheart.00678.2003

76. Hernandez-Resendiz S, Prunier F, Girao H, Dorn G, Hausenloy DJ (2020) Targeting mitochondrial fusion and fission proteins for cardioprotection. J Cell Mol Med 24:6571-6585. https://doi.org/ $10.1111 /$ jcmm. 15384

77. Heusch G (2015) Molecular basis of cardioprotection: signal transduction in ischemic pre-, post- and remote conditioning. Circ Res 116:674-699. https://doi.org/10.1161/CIRCRESAHA. 116.305348

78. Heusch G, Boengler K, Schulz R (2010) Inhibition of mitochondrial permeability transition pore opening: the holy grail of cardioprotection. Basic Res Cardiol 105:151-154. https://doi.org/ 10.1007/s00395-009-0080-9

79. Heusch G, Musiolik J, Gedik N, Skyschally A (2011) Mitochondrial STAT3 activation and cardioprotection by ischemic postconditioning in pigs with regional myocardial ischemia/ reperfusion. Circ Res 109:1302-1308. https://doi.org/10.1161/ CIRCRESAHA.111.255604

80. Heusch G, Musiolik J, Kottenberg E, Peters J, Jakob H, Thielmann M (2012) STAT5 activation and cardioprotection by remote ischemic preconditioning in humans: short communication. Circ Res 110:111-115. https://doi.org/10.1161/CIRCR ESAHA.111.259556

81. Heusch G, Rassaf T (2016) Time to give up on cardioprotection? Circ Res 119:676-695. https://doi.org/10.1161/CIRCR ESAHA.116.308736

82. Hildebrandt HA, Kreienkamp V, Gent S, Kahlert P, Heusch G, Kleinbongard P (2016) Kinetics and signal activation properties of circulating factor(s) from healthy volunteers undergoing remote ischemic pre-conditioning. JACC Basic Transl Sci 1:3-13. https://doi.org/10.1016/j.jacbts.2016.01.007

83. Hilfiker-Kleiner D, Hilfiker A, Fuchs M, Kaminski K, Schaefer A, Schieffer B, Hillmer A, Schmiedl A, Ding Z, Podewski E, Podewski E, Poli V, Schneider MD, Schulz R, Park J-K, Wollert KC, Drexler H (2004) Signal transducer and activator of transcription 3 is required for myocardial capillary growth, control of interstitial matrix deposition, and heart protection from ischemic injury. Circ Res 95:187-195. https://doi.org/10. 1161/01.RES.0000134921.50377.61

84. Hilfiker-Kleiner D, Kaminski K, Podewski E, Bonda T, Schaefer A, Sliwa K, Forster O, Quint A, Landmesser U, Doerries C, Luchtefeld M, Poli V, Schneider MD, Balligand JL, Desjardins F, Ansari A, Struman I, Nguyen NQ, Zschemisch NH, Klein G, Heusch G, Schulz R, Hilfiker A, Drexler H (2007) A cathepsin D-cleaved $16 \mathrm{kDa}$ form of prolactin mediates postpartum cardiomyopathy. Cell 128:589-600. https:// doi.org/10.1016/j.cell.2006.12.036
85. Ho AFW, Chong J, Ong MEH, Hausenloy DJ (2020) Remote ischemic conditioning in emergency medicine-clinical frontiers and research opportunities. Shock 53:269-276. https://doi.org/ 10.1097/SHK.0000000000001362

86. Holopainen T, Räsänen M, Anisimov A, Tuomainen T, Zheng W, Tvorogov D, Hulmi JJ, Andersson LC, Cenni B, Tavi P, Mervaala E, Kivelä R, Alitalo K (2015) Endothelial Bmx tyrosine kinase activity is essential for myocardial hypertrophy and remodeling. Proc Natl Acad Sci U S A 112:13063-13068. https://doi.org/10.1073/pnas.1517810112

87. Hu H, Nan J, Sun Y, Zhu D, Xiao C, Wang Y, Zhu L, Wu Y, Zhao J, Wu R, Chen J, Yu H, Hu X, Zhu W, Wang J (2017) Electron leak from NDUFA13 within mitochondrial complex I attenuates ischemia-reperfusion injury via dimerized STAT3. Proc Natl Acad Sci USA 114:11908-11913. https://doi.org/10. 1073/pnas. 1704723114

88. Huang C-H, Tsai M-S, Chiang C-Y, Su Y-J, Wang T-D, Chang W-T, Chen H-W, Chen W-J (2015) Activation of mitochondrial STAT-3 and reduced mitochondria damage during hypothermia treatment for post-cardiac arrest myocardial dysfunction. Basic Res Cardiol 110:59. https://doi.org/10.1007/ s00395-015-0516-3

89. Inserte J, Ruiz-Meana M, Rodríguez-Sinovas A, Barba I, GarciaDorado D (2011) Contribution of delayed intracellular $\mathrm{pH}$ recovery to ischemic postconditioning protection. Antioxid Redox Signal 14:923-939. https://doi.org/10.1089/ars.2010.3312

90. Izem-Meziane M, Djerdjouri B, Rimbaud S, Caffin F, Fortin D, Garnier A, Veksler V, Joubert F, Ventura-Clapier R (2012) Catecholamine-induced cardiac mitochondrial dysfunction and mPTP opening: protective effect of curcumin. Am J Physiol Heart Circ Physiol 302:H665-H674. https://doi.org/10.1152/ ajpheart.00467.2011

91. Jain S, Wei J, Mitrani LR, Bishopric NH (2012) Auto-acetylation stabilizes p300 in cardiac myocytes during acute oxidative stress, promoting STAT3 accumulation and cell survival. Breast Cancer Res Treat 135:103-114. https://doi.org/10.1007/ s10549-012-2069-6

92. Jay DB, Papaharalambus CA, Seidel-Rogol B, Dikalova AE, Lassègue B, Griendling KK (2008) Nox5 mediates PDGFinduced proliferation in human aortic smooth muscle cells. Free Radic Biol Med 45:329-335. https://doi.org/10.1016/j.freeradbio med.2008.04.024

93. Jeong K, Kwon H, Min C, Pak Y (2009) Modulation of the caveolin-3 localization to caveolae and STAT3 to mitochondria by catecholamine-induced cardiac hypertrophy in H9c2 cardiomyoblasts. Exp Mol Med 41:226-235. https://doi.org/10.3858/ emm.2009.41.4.025

94. Jones SP, Tang X-L, Guo Y, Steenbergen C, Lefer DJ, Kukreja RC, Kong M, Li Q, Bhushan S, Zhu X, Du J, Nong Y, Stowers HL, Kondo K, Hunt GN, Goodchild TT, Orr A, Chang CC, Ockaili R, Salloum FN, Bolli R (2015) The NHLBI-Sponsored Consortium for preclinicAl assESsment of cARdioprotective Therapies (CAESAR): A New Paradigm for Rigorous, Accurate, and Reproducible Evaluation of Putative Infarct-Sparing Interventions in Mice, Rabbits, and Pigs. Circ Res 116:572-586. https://doi.org/10.1161/CIRCRESAHA.116.305462

95. Kim E, Kim M, Woo D-H, Shin Y, Shin J, Chang N, Oh YT, Kim H, Rheey J, Nakano I, Lee C, Joo KM, Rich JN, Nam D-H, Lee J (2013) Phosphorylation of EZH2 activates STAT3 signaling via STAT3 methylation and promotes tumorigenicity of glioblastoma stem-like cells. Cancer Cell 23:839-852. https://doi.org/ 10.1016/j.ccr.2013.04.008

96. Kim J, Won J-S, Singh AK, Sharma AK, Singh I (2013) STAT3 Regulation by S-nitrosylation: implication for inflammatory disease. Antioxid Redox Signal 20:2514-2527. https://doi.org/10. 1089/ars.2013.5223 
97. Kleinbongard P, Amanakis G, Skyschally A, Heusch G (2018) Reflection of cardioprotection by remote ischemic perconditioning in attenuated ST-segment elevation during ongoing coronary occlusion in pigs: evidence for cardioprotection from ischemic injury. Circ Res 122:1102-1108. https://doi.org/10.1161/CIRCR ESAHA.118.312784

98. Kleinbongard P, Bøtker HE, Ovize M, Hausenloy DJ, Heusch G (2020) Co-morbidities and co-medications as confounders of cardioprotection-does it matter in the clinical setting? Br J Pharmacol 177:5252-5269. https://doi.org/10.1111/bph.14839

99. Kleinbongard P, Gedik N, Kirca M, Stoian L, Frey U, Zandi A, Thielmann M, Jakob H, Peters J, Kamler M, Heusch G (2018) Mitochondrial and contractile function of human right atrial tissue in response to remote ischemic conditioning. J Am Heart Assoc 7:e009540. https://doi.org/10.1161/JAHA.118.009540

100. Kleinbongard P, Skyschally A, Gent S, Pesch M, Heusch G (2017) STAT3 as a common signal of ischemic conditioning: a lesson on "rigor and reproducibility" in preclinical studies on cardioprotection. Basic Res Cardiol 113:3. https://doi.org/10. 1007/s00395-017-0660-z

101. Kottenberg E, Musiolik J, Thielmann M, Jakob H, Peters J, Heusch G (2014) Interference of propofol with signal transducer and activator of transcription 5 activation and cardioprotection by remote ischemic preconditioning during coronary artery bypass grafting. J Thorac Cardiovasc Surg 147:376-382. https://doi.org/ 10.1016/j.jtcvs.2013.01.005

102. Krylatov AV, Maslov LN, Voronkov NS, Boshchenko AA, Popov SV, Gomez L, Wang H, Jaggi AS, Downey JM (2018) Reactive oxygen species as intracellular signaling molecules in the cardiovascular system. Curr Cardiol Rev 14:290-300. https://doi.org/ $10.2174 / 1573403$ X14666180702152436

103. Kuchay S, Giorgi C, Simoneschi D, Pagan J, Missiroli S, Saraf A, Florens L, Washburn MP, Collazo-Lorduy A, Castillo-Martin M, Cordon-Cardo C, Sebti SM, Pinton P, Pagano M (2017) PTEN counteracts FBXL2 to promote IP3R3- and $\mathrm{Ca}^{2+}$-mediated apoptosis limiting tumour growth. Nature 546:554-558. https://doi. org/10.1038/nature22965

104. Kulek AR, Anzell A, Wider JM, Sanderson TH, Przyklenk K (2020) Mitochondrial quality control: role in cardiac models of lethal ischemia-reperfusion injury. Cells 9:214. https://doi.org/ 10.3390/cells9010214

105. Kulinski JM, Muñoz-Cano R, Olivera A (2016) Sphingosine1-phosphate and other lipid mediators generated by mast cells as critical players in allergy and mast cell function. Eur J Pharmacol 778:56-67. https://doi.org/10.1016/j.ejphar.2015.02.058

106. Kunisada K, Negoro S, Tone E, Funamoto M, Osugi T, Yamada S, Okabe M, Kishimoto T, Yamauchi-Takihara K (2000) Signal transducer and activator of transcription 3 in the heart transduces not only a hypertrophic signal but a protective signal against doxorubicin-induced cardiomyopathy. Proc Natl Acad Sci U S A 97:315-319. https://doi.org/10.1073/pnas.97.1.315

107. Kurdi M, Booz GW (2007) Evidence that IL-6-type cytokine signaling in cardiomyocytes is inhibited by oxidative stress: parthenolide targets JAK1 activation by generating ROS. J Cell Physiol 212:424-431. https://doi.org/10.1002/jcp.21033

108. Kuznetsov AV, Javadov S, Margreiter R, Grimm M, Hagenbuchner J, Ausserlechner MJ (2019) The role of mitochondria in the mechanisms of cardiac ischemia-reperfusion injury. Antioxidants (Basel) 8:E454. https://doi.org/10.3390/antiox8100454

109. Kwak H-J, Park KM, Choi H-E, Park H-Y (2009) Protective mechanisms of NO preconditioning against NO-induced apoptosis in H9c2 cells: role of PKC and COX-2. Free Radic Res 43:744-752. https://doi.org/10.1080/10715760903040602

110. Kwon T, Bak Y, Park Y-H, Jang G-B, Nam J-S, Yoo JE, Park YN, Bak IS, Kim J-M, Yoon D-Y, Yu D-Y (2016) Peroxiredoxin II is essential for maintaining stemness by redox regulation in liver cancer cells. Stem Cells 34:1188-1197. https://doi.org/10.1002/ stem. 2323

111. La Sala G, Michiels C, Kükenshöner T, Brandstoetter T, Maurer B, Koide A, Lau K, Pojer F, Koide S, Sexl V, Dumoutier L, Hantschel O (2020) Selective inhibition of STAT3 signaling using monobodies targeting the coiled-coil and N-terminal domains. Nat Comm 11:4115. https://doi.org/10.1038/ s41467-020-17920-z

112. Lacerda L, McCarthy J, Mungly SFK, Lynn EG, Sack MN, Opie LH, Lecour S (2010) TNF $\alpha$ protects cardiac mitochondria independently of its cell surface receptors. Basic Res Cardiol 105:751-762. https://doi.org/10.1007/s00395-010-0113-4

113. Lacerda L, Somers S, Opie LH, Lecour S (2009) Ischaemic postconditioning protects against reperfusion injury via the SAFE pathway. Cardiovasc Res 84:201-208. https://doi.org/10.1093/ cvr/cvp274

114. Lamont KT, Somers S, Lacerda L, Opie LH, Lecour S (2011) Is red wine a SAFE sip away from cardioprotection? Mechanisms involved in resveratrol- and melatonin-induced cardioprotection. J Pineal Res 50:374-380. https://doi.org/10.1111/j.1600-079X. 2010.00853.x

115. Lecour S, James RW (2011) When are pro-inflammatory cytokines SAFE in heart failure? Eur Heart J 32:680-685. https:// doi.org/10.1093/eurheartj/ehq484

116. Lecour S, Rochette L, Opie L (2005) Free radicals trigger TNF alpha-induced cardioprotection. Cardiovasc Res 65:239-243. https://doi.org/10.1016/j.cardiores.2004.10.003

117. Lecour S, Smith RM, Woodward B, Opie LH, Rochette L, Sack MN (2002) Identification of a novel role for sphingolipid signaling in TNF alpha and ischemic preconditioning mediated cardioprotection. J Mol Cell Cardiol 34:509-518. https://doi.org/ 10.1006/jmcc.2002.1533

118. Lecour S, Suleman N, Deuchar GA, Somers S, Lacerda L, Huisamen B, Opie LH (2005) Pharmacological preconditioning with tumor necrosis factor-alpha activates signal transducer and activator of transcription-3 at reperfusion without involving classic prosurvival kinases (Akt and extracellular signalregulated kinase). Circulation 112:3911-3918. https://doi.org/ 10.1161/CIRCULATIONAHA.105.581058

119. Lee H, Jeong AJ, Ye S-K (2019) Highlighted STAT3 as a potential drug target for cancer therapy. BMB Rep 52:415-423. https://doi.org/10.5483/BMBRep.2019.52.7.152

120. Lee H, Zhang P, Herrmann A, Yang C, Xin H, Wang Z, Hoon DSB, Forman SJ, Jove R, Riggs AD, Yu H (2012) Acetylated STAT3 is crucial for methylation of tumor-suppressor gene promoters and inhibition by resveratrol results in demethylation. Proc Natl Acad Sci U S A 109:7765-7769. https://doi. org/10.1073/pnas.1205132109

121. Lee JE, Yang Y-M, Liang F-X, Gough DJ, Levy DE, Sehgal PB (2012) Nongenomic STAT5-dependent effects on Golgi apparatus and endoplasmic reticulum structure and function. Am J Physiol Cell Physiol 302:C804-C820. https://doi.org/10.1152/ ajpcell.00379.2011

122. Lee JK, Edderkaoui M, Truong P, Ohno I, Jang K-T, Berti A, Pandol SJ, Gukovskaya AS (2007) NADPH oxidase promotes pancreatic cancer cell survival via inhibiting JAK2 dephosphorylation by tyrosine phosphatases. Gastroenterology 133:16371648. https://doi.org/10.1053/j.gastro.2007.08.022

123. Lee T-M, Chang N-C, Lin S-Z (2017) Dapagliflozin, a selective SGLT2 Inhibitor, attenuated cardiac fibrosis by regulating the macrophage polarization via STAT3 signaling in infarcted rat hearts. Free Radic Biol Med 104:298-310. https://doi.org/10. 1016/j.freeradbiomed.2017.01.035

124. Lei S, Su W, Xia Z-Y, Wang Y, Zhou L, Qiao S, Zhao B, Xia $Z$ (2019) Hyperglycemia-induced oxidative stress abrogates remifentanil preconditioning-mediated cardioprotection in 
diabetic rats by impairing caveolin-3-modulated PI3K/Akt and JAK2/STAT3 signaling. Oxid Med Cell Longev 2019:1-19. https://doi.org/10.1155/2019/9836302

125. Lemoine S, Zhu L, Legallois D, Massetti M, Manrique A, Hanouz J-L (2013) Atorvastatin-induced cardioprotection of human myocardium is mediated by the inhibition of mitochondrial permeability transition pore opening via tumor necrosis factor- $\alpha$ and Janus kinase/signal transducers and activators of transcription pathway. Anesthesiology 118:1373-1384. https:// doi.org/10.1097/ALN.0b013e31828a7039

126. Lesnefsky EJ, Moghaddas S, Tandler B, Kerner J, Hoppel CL (2001) Mitochondrial dysfunction in cardiac disease: ischemia-reperfusion, aging, and heart failure. J Mol Cell Cardiol 33:1065-1089. https://doi.org/10.1006/jmcc.2001.1378

127. Lesnefsky EJ, Chen Q, Hoppel CL (2016) Mitochondrial Metabolism in Aging Heart. Circ Res 118:1593-1611. https:// doi.org/10.1161/CIRCRESAHA.116.307505

128. Letts JA, Fiedorczuk K, Sazanov LA (2016) The architecture of respiratory supercomplexes. Nature 537:644-648. https:// doi.org/10.1038/nature19774

129. Levy DE, Darnell JE (2002) Stats: transcriptional control and biological impact. Nat Rev Mol Cell Biol 3:651-662. https:// doi.org/10.1038/nrm909

130. Li GC, Vasquez JA, Gallagher KP, Lucchesi BR (1990) Myocardial protection with preconditioning. Circulation 82:609619. https://doi.org/10.1161/01.CIR.82.2.609

131. Li H, Liu Z, Wang J, Wong GT, Cheung CW, Zhang L, Chen C, Xia Z, Irwin MG (2013) Susceptibility to myocardial ischemia reperfusion injury at early stage of type 1 diabetes in rats. Cardiovasc Diabetol 12:133. https://doi.org/10.1186/ 1475-2840-12-133

132. Li L, Cheung S, Evans EL, Shaw PE (2010) Modulation of gene expression and tumor cell growth by redox modification of STAT3. Cancer Res 70:8222-8232. https://doi.org/10.1158/ 0008-5472.CAN-10-0894

133. Lieder HR, Kleinbongard P, Skyschally A, Hagelschuer H, Chilian WM, Heusch G (2018) Vago-splenic axis in signal transduction of remote ischemic preconditioning in pigs and rats. Circ Res 123:1152-1163. https://doi.org/10.1161/CIRCR ESAHA.118.313859

134. Linher-Melville K, Singh G (2017) The complex roles of STAT3 and STAT5 in maintaining redox balance: lessons from STAT-mediated xCT expression in cancer cells. Mol Cell Endocrinol 451:40-52. https://doi.org/10.1016/j.mce.2017.02. 014

135. Liu B, Palmfeldt J, Lin L, Colaço A, Clemmensen KKB, Huang J, Xu F, Liu X, Maeda K, Luo Y, Jäättelä M (2018) STAT3 associates with vacuolar H+-ATPase and regulates cytosolic and lysosomal pH. Cell Res 28:996-1012. https://doi.org/10.1038/ s41422-018-0080-0

136. Liu X, Chen H, Yan Z, Du L, Huang D, Gao WD, Hu Z (2021) Remote liver ischemic preconditioning attenuates myocardial ischemia/reperfusion injury in streptozotocin-induced diabetic rats. Sci Rep 11:1903. https://doi.org/10.1038/ s41598-021-81422-1

137. Liu Y, Dong Gao W, O’Rourke B, Marban E (1996) Synergistic modulation of ATP-sensitive $\mathrm{K}+$ currents by protein kinase $\mathrm{c}$ and adenosine. Circ Res 78:443-454. https://doi.org/10.1161/ 01.RES.78.3.443

138. Liu Y, Ytrehus K, Downey JM (1994) Evidence that translocation of protein kinase $\mathrm{c}$ is a key event during ischemic preconditioning of rabbit myocardium. J Mol Cell Cardiol 26:661-668. https:// doi.org/10.1006/jmcc.1994.1078

139. Lucchinetti E, Bestmann L, Feng J, Freidank H, Clanachan AS, Finegan BA, Zaugg M (2012) Remote ischemic preconditioning applied during isoflurane inhalation provides no benefit to the myocardium of patients undergoing on-pump coronary artery bypass graft surgery: lack of synergy or evidence of antagonism in cardioprotection? Anesthesiology 116:296-310. https://doi. org/10.1097/ALN.0b013e318242349a

140. Lufei C, Ma J, Huang G, Zhang T, Novotny-Diermayr V, Ong CT, Cao X (2003) GRIM-19, a death-regulatory gene product, suppresses Stat 3 activity via functional interaction. EMBO J 22:1325-1335. https://doi.org/10.1093/emboj/cdg135

141. Maceyka M, Spiegel S (2014) Sphingolipid metabolites in inflammatory disease. Nature 510:58-67. https://doi.org/10. 1038/nature 13475

142. Macias E, Rao D, Carbajal S, Kiguchi K, DiGiovanni J (2014) Stat3 binds to mitochondrial DNA and regulates mitochondrial gene expression in keratinocytes. J Invest Dermatol 134:19711980. https://doi.org/10.1038/jid.2014.68

143. Maierean S, Serban M-C, Rizzo M, Lippi G, Sahebkar A, Banach M (2017) The potential role of mitochondrial ATP synthase inhibitory factor 1 (IF1) in coronary heart disease: a literature review. Lipids Health Dis 16:35. https://doi.org/10.1186/ s12944-017-0430-9

144. Maroko PR, Libby P, Covell JW, Sobel BE, Ross J, Braunwald E (1972) Precordial S-T segment elevation mapping: an atraumatic method for assessing alterations in the extent of myocardial ischemic injury: the effects of pharmacologic and hemodynamic interventions. Am J Cardiol 29:223-230. https://doi.org/10.1016/ 0002-9149(72)90633-9

145. Matsui T, Li L, Wu JC, Cook SA, Nagoshi T, Picard MH, Liao R, Rosenzweig A (2002) Phenotypic spectrum caused by transgenic overexpression of activated Akt in the heart. J Biol Chem 277:22896-22901. https://doi.org/10.1074/jbc.M200347200

146. Mayr M, Metzler B, Chung YL, McGregor E, Mayr U, Troy $\mathrm{H}$, Hu Y, Leitges M, Pachinger O, Griffiths JR, Dunn MJ, Xu $\mathrm{Q}$ (2004) Ischemic preconditioning exaggerates cardiac damage in PKC-delta null mice. Am J Physiol Heart Circ Physiol 287:H946-H956. https://doi.org/10.1152/ajpheart.00878.2003

147. McCormick J, Barry SP, Sivarajah A, Stefanutti G, Townsend PA, Lawrence KM, Eaton S, Knight RA, Thiemermann C, Latchman DS, Stephanou A (2006) Free radical scavenging inhibits STAT phosphorylation following in vivo ischemia/reperfusion injury. FASEB J 20:2115-2117. https://doi.org/10.1096/fj.066188fje

148. McGaffin KR, Sun C-K, Rager JJ, Romano LC, Zou B, Mathier MA, O’Doherty RM, McTiernan CF, O’Donnell CP (2008) Leptin signalling reduces the severity of cardiac dysfunction and remodelling after chronic ischaemic injury. Cardiovasc Res 77:54-63. https://doi.org/10.1093/cvr/cvm023

149. McGaffin KR, Witham WG, Yester KA, Romano LC, O’Doherty RM, McTiernan CF, O'Donnell CP (2011) Cardiac-specific leptin receptor deletion exacerbates ischaemic heart failure in mice. Cardiovasc Res 89:60-71. https://doi.org/10.1093/cvr/cvq288

150. Means CK, Xiao C-Y, Li Z, Zhang T, Omens JH, Ishii I, Chun J, Brown JH (2007) Sphingosine 1-phosphate S1P2 and S1P3 receptor-mediated Akt activation protects against in vivo myocardial ischemia-reperfusion injury. Am J Physiol Heart Circ Physiol 292:H2944-H2951. https://doi.org/10.1152/ajpheart. 01331.2006

151. Meier JA, Hyun M, Cantwell M, Raza A, Mertens C, Raje V, Sisler J, Tracy E, Torres-Odio S, Gispert S, Shaw PE, Baumann H, Bandyopadhyay D, Takabe K, Larner AC (2017) Stressinduced dynamic regulation of mitochondrial STAT3 and its association with cyclophilin D reduce mitochondrial ROS production. Sci Signal. https://doi.org/10.1126/scisignal.aag2588

152. Meybohm P, Zacharowski K, Cremer J, Roesner J, Kletzin F, Schaelte G, Felzen M, Strouhal U, Reyher C, Heringlake M, Schön J, Brandes I, Bauer M, Knuefermann P, Wittmann M, Hachenberg T, Schilling T, Smul T, Maisch S, Sander M, 
Moormann T, Boening A, Weigand MA, Laufenberg R, Werner C, Winterhalter M, Treschan T, Stehr SN, Reinhart K, Hasenclever D, Brosteanu O, Bein B, RIP Heart-Study Investigator Group (2012) Remote ischaemic preconditioning for heart surgery. The study design for a multi-center randomized doubleblinded controlled clinical trial-the RIPHeart-Study. Eur Heart J 33:1423-1426

153. Murry CE, Jennings RB, Reimer KA (1986) Preconditioning with ischemia: a delay of lethal cell injury in ischemic myocardium. Circulation 74:1124-1136. https://doi.org/10.1161/01. CIR.74.5.1124

154. Myers MG (2009) Cell biology. Moonlighting in mitochondria. Science 323:723-724. https://doi.org/10.1126/science.1169660

155. Nagata T, Yasukawa H, Kyogoku S, Oba T, Takahashi J, Nohara S, Minami T, Mawatari K, Sugi Y, Shimozono K, Pradervand S, Hoshijima M, Aoki H, Fukumoto Y, Imaizumi T (2015) Cardiacspecific SOCS3 deletion prevents in vivo myocardial ischemia reperfusion injury through sustained activation of cardioprotective signaling molecules. PLoS ONE 10:e0127942. https://doi. org/10.1371/journal.pone.0127942

156. Nan J, Hu H, Sun Y, Zhu L, Wang Y, Zhong Z, Zhao J, Zhang $\mathrm{N}$, Wang Y, Wang Y, Ye J, Zhang L, Hu X, Zhu W, Wang J (2017) TNFR2 stimulation promotes mitochondrial fusion via Stat3- and NF-kB-dependent activation of OPA1 expression. Circ Res 121:392-410. https://doi.org/10.1161/CIRCRESAHA.117. 311143

157. Negoro S, Kunisada K, Tone E, Funamoto M, Oh H, Kishimoto T, Yamauchi-Takihara K (2000) Activation of JAK/STAT pathway transduces cytoprotective signal in rat acute myocardial infarction. Cardiovasc Res 47:797-805. https://doi.org/10.1016/ s0008-6363(00)00138-3

158. Ng DCH, Lin BH, Lim CP, Huang G, Zhang T, Poli V, Cao X (2006) Stat3 regulates microtubules by antagonizing the depolymerization activity of stathmin. J Cell Biol 172:245-257. https://doi.org/10.1083/jcb.200503021

159. Nie Y, Erion DM, Yuan Z, Dietrich M, Shulman GI, Horvath TL, Gao Q (2009) STAT3 inhibition of gluconeogenesis is downregulated by SirT1. Nat Cell Biol 11:492-500. https://doi.org/ $10.1038 / \mathrm{ncb} 1857$

160. Nikolaou PE, Efentakis P, Abu Qourah F, Femminò S, Makridakis M, Kanaki Z, Varela A, Tsoumani M, Davos CH, Dimitriou CA, Tasouli A, Dimitriadis G, Kostomitsopoulos N, Zuurbier CJ, Vlahou A, Klinakis A, Brizzi MF, Iliodromitis EK, Andreadou I (2021) Chronic empagliflozin treatment reduces myocardial infarct size in nondiabetic mice through stat-3-mediated protection on microvascular endothelial cells and reduction of oxidative stress. Antioxid Redox Signal 34:551-571. https://doi.org/ 10.1089/ars.2019.7923

161. Nolan JP, Morley PT, Vanden Hoek TL, Hickey RW, Kloeck WGJ, Billi J, Böttiger BW, Morley PT, Nolan JP, Okada K, Reyes C, Shuster M, Steen PA, Weil MH, Wenzel V, Hickey RW, Carli P, Vanden Hoek TL, Atkins D, International Liaison Committee on Resuscitation (2003) Therapeutic hypothermia after cardiac arrest: an advisory statement by the advanced life support task force of the International Liaison Committee on Resuscitation. Circulation 108:118-121. https://doi.org/10.1161/01.CIR.00000 79019.02601 .90

162. Ong S-B, Dongworth RK, Cabrera-Fuentes HA, Hausenloy DJ (2015) Role of the MPTP in conditioning the heart - translatability and mechanism. Br J Pharmacol 172:2074-2084. https:// doi.org/10.1111/bph.13013

163. Pagliaro P, Aragno M, Penna C (2020) Role of temperature in myocardial ischemic injury and protection by conditioning. Cond Med 3:31-46

164. Pagliaro P, Moro F, Tullio F, Perrelli M-G, Penna C (2011) Cardioprotective pathways during reperfusion: focus on redox signaling and other modalities of cell signaling. Antioxid Redox Signal 14:833-850. https://doi.org/10.1089/ars.2010.3245

165. Pagliaro P, Penna C (2017) Hypertension, hypertrophy, and reperfusion injury. J Cardiovasc Med (Hagerstown) 18:131-135. https://doi.org/10.2459/JCM.0000000000000435

166. Penna C, Alloatti G, Cappello S, Gattullo D, Berta G, Mognetti B, Losano G, Pagliaro P (2005) Platelet-activating factor induces cardioprotection in isolated rat heart akin to ischemic preconditioning: role of phosphoinositide 3-kinase and protein kinase C activation. Am J Physiol Heart Circ Physiol 288:H2512-H2520. https://doi.org/10.1152/ajpheart.00599.2004

167. Penna C, Andreadou I, Aragno M, Beauloye C, Bertrand L, Lazou A, Falcão-Pires I, Bell R, Zuurbier CJ, Pagliaro P, Hausenloy DJ (2020) Effect of hyperglycaemia and diabetes on acute myocardial ischaemia-reperfusion injury and cardioprotection by ischaemic conditioning protocols. Br J Pharmacol 177:53125335. https://doi.org/10.1111/bph.14993

168. Penna C, Granata R, Tocchetti CG, Gallo MP, Alloatti G, Pagliaro $P$ (2015) Endogenous cardioprotective agents: role in pre and postconditioning. Curr Drug Targets 16:843-867. https://doi.org/ 10.2174/1389450116666150309115536

169. Penna C, Pagliaro P, Rastaldo R, Di Pancrazio F, Lippe G, Gattullo D, Mancardi D, Samaja M, Losano G, Mavelli I (2004) F0F1 ATP synthase activity is differently modulated by coronary reactive hyperemia before and after ischemic preconditioning in the goat. Am J Physiol Heart Circ Physiol 287:H2192-H2200. https://doi.org/10.1152/ajpheart.00327.2004

170. Phillips D, Reilley MJ, Aponte AM, Wang G, Boja E, Gucek M, Balaban RS (2010) Stoichiometry of STAT3 and mitochondrial proteins: Implications for the regulation of oxidative phosphorylation by protein-protein interactions. J Biol Chem 285:2353223536. https://doi.org/10.1074/jbc.C110.152652

171. Pickard JMJ, Bøtker HE, Crimi G, Davidson B, Davidson SM, Dutka D, Ferdinandy P, Ganske R, Garcia-Dorado D, Giricz Z, Gourine AV, Heusch G, Kharbanda R, Kleinbongard P, MacAllister R, McIntyre C, Meybohm P, Prunier F, Redington A, Robertson NJ, Suleiman MS, Vanezis A, Walsh S, Yellon DM, Hausenloy DJ (2014) Remote ischemic conditioning: from experimental observation to clinical application: report from the 8th Biennial Hatter Cardiovascular Institute Workshop. Basic Res Cardiol 110:453. https://doi.org/10.1007/ s00395-014-0453-6

172. Rahman IA, Mascaro JG, Steeds RP, Frenneaux MP, Nightingale P, Gosling P, Townsend P, Townend JN, Green D, Bonser RS (2010) Remote ischemic preconditioning in human coronary artery bypass surgery: from promise to disappointment? Circulation 122:S53-59. https://doi.org/10.1161/CIRCULATIONAHA. 109.926667

173. Rawlings JS, Rosler KM, Harrison DA (2004) The JAK/STAT signaling pathway. J Cell Sci 117:1281-1283. https://doi.org/10. 1242/jcs.00963

174. Ray S, Zhao Y, Jamaluddin M, Edeh CB, Lee C, Brasier AR (2014) Inducible STAT3 NH2 terminal mono-ubiquitination promotes BRD4 complex formation to regulate apoptosis. Cell Sign 26:1445-1455. https://doi.org/10.1016/j.cellsig.2014.03.007

175. Remondino A, Kwon SH, Communal C, Pimentel DR, Sawyer DB, Singh K, Colucci WS (2003) Beta-adrenergic receptorstimulated apoptosis in cardiac myocytes is mediated by reactive oxygen species/c-Jun NH2-terminal kinase-dependent activation of the mitochondrial pathway. Circ Res 92:136-138. https://doi. org/10.1161/01.res.0000054624.03539.b4

176. Rizzuto R, Pinton P, Carrington W, Fay FS, Fogarty KE, Lifshitz LM, Tuft RA, Pozzan T (1998) Close contacts with the endoplasmic reticulum as determinants of mitochondrial $\mathrm{Ca} 2+$ responses. Science 280:1763-1766. https://doi.org/10.1126/scien ce. 280.5370 .1763 
177. Rong J, Li L, Jing L, Fang H, Peng S (2016) JAK2/STAT3 pathway mediates protection of metallothionein against doxorubicininduced cytotoxicity in mouse cardiomyocytes. Int J Toxicol 35:317-326. https://doi.org/10.1177/1091581815614261

178. Roth GA, Mensah GA, Johnson CO, Addolorato G, Ammirati E, Baddour LM, Barengo NC, Beaton AZ, Benjamin EJ, Benziger CP, Bonny A, Brauer M, Brodmann M, Cahill TJ, Carapetis J, Catapano AL, Chugh SS, Cooper LT, Coresh J, Criqui M, DeCleene N, Eagle KA, Emmons-Bell S, Feigin VL, FernándezSolà J, Fowkes G, Gakidou E, Grundy SM, He FJ, Howard G, Hu F, Inker L, Karthikeyan G, Kassebaum N, Koroshetz W, Lavie C, Lloyd-Jones D, Lu HS, Mirijello A, Temesgen AM, Mokdad A, Moran AE, Muntner P, Narula J, Neal B, Ntsekhe M, Moraes de Oliveira G, Otto C, Owolabi M, Pratt M, Rajagopalan S, Reitsma M, Ribeiro ALP, Rigotti N, Rodgers A, Sable C, Shakil S, SliwaHahnle K, Stark B, Sundström J, Timpel P, Tleyjeh IM, Valgimigli M, Vos T, Whelton PK, Yacoub M, Zuhlke L, Murray C, Fuster V, GBD-NHLBI-JACC Global Burden of Cardiovascular Diseases Writing Group (2020) Global Burden of Cardiovascular Diseases and Risk Factors, 1990-2019: Update From the GBD 2019 Study. J Am Coll Cardiol 76:2982-3021. https://doi.org/ 10.1016/j.jacc.2020.11.010

179. Russo I, Femminò S, Barale C, Tullio F, Geuna S, Cavalot F, Pagliaro P, Penna C (2018) Cardioprotective properties of human platelets are lost in uncontrolled diabetes mellitus: a study in isolated rat hearts. Front Physiol 9:875. https://doi.org/10.3389/ fphys.2018.00875

180. Sanderson TH, Reynolds CA, Kumar R, Przyklenk K, Hüttemann M (2013) Molecular mechanisms of ischemia-reperfusion injury in brain: pivotal role of the mitochondrial membrane potential in reactive oxygen species generation. Mol Neurobiol 47:9-23. https://doi.org/10.1007/s12035-012-8344-Z

181. Sarafian TA, Montes C, Imura T, Qi J, Coppola G, Geschwind DH, Sofroniew MV (2010) Disruption of astrocyte STAT3 signaling decreases mitochondrial function and increases oxidative stress in vitro. PLoS ONE 5:e9532. https://doi.org/10.1371/journ al.pone.0009532

182. Schulman D, Latchman DS, Yellon DM (2002) Urocortin protects the heart from reperfusion injury via upregulation of $\mathrm{p} 42 /$ p44 MAPK signaling pathway. Am J Physiol Heart Circ Physiol 283:H1481-H1488. https://doi.org/10.1152/ajpheart.01089.2001

183. Schust J, Sperl B, Hollis A, Mayer TU, Berg T (2006) Stattic: A small-molecule inhibitor of STAT3 activation and dimerization. Chem Biol 13:1235-1242. https://doi.org/10.1016/j.chembiol. 2006.09.018

184. Sgrignani J, Garofalo M, Matkovic M, Merulla J, Catapano CV, Cavalli A (2018) Structural biology of STAT3 and its implications for anticancer therapies development. Int J Mol Sci 19:1591. https://doi.org/10.3390/ijms19061591

185. Shao Z, Bhattacharya K, Hsich E, Park L, Walters B, Germann U, Wang Y-M, Kyriakis J, Mohanlal R, Kuida K, Namchuk M, Salituro F, Yao Y, Hou W, Chen X, Aronovitz M, Tsichlis PN, Bhattacharya S, Force T, Kilter H (2006) c-Jun N-terminal kinases mediate reactivation of Akt and cardiomyocyte survival after hypoxic injury in vitro and in vivo. Circ Res 98:111-118. https://doi.org/10.1161/01.RES.0000197781.20524.b9

186. Shi A, Tao Z, Wei P, Zhao J (2016) Epidemiological aspects of heart diseases. Exp Ther Med 12:1645-1650. https://doi.org/10. 3892/etm.2016.3541

187. Shravah J, Wang B, Pavlovic M, Kumar U, Chen DD, Luo H, Ansley DM (2014) Propofol mediates signal transducer and activator of transcription 3 activation and crosstalk with phosphoinositide 3-kinase/AKT. JAKSTAT 3:e29554. https://doi.org/10. $4161 /$ jkst.29554
188. Simon AR, Rai U, Fanburg BL, Cochran BH (1998) Activation of the JAK-STAT pathway by reactive oxygen species. Am J Physiol Cell Physiol 275:C1640-C1652. https://doi.org/10.1152/ajpcell. 1998.275.6.C1640

189. Skyschally A, van Caster P, Boengler K, Gres P, Musiolik J, Schilawa D, Schulz R, Heusch G (2009) Ischemic postconditioning in pigs. Circ Res 104:15-18. https://doi.org/10.1161/CIRCR ESAHA.108.186429

190. Skyschally A, Gent S, Amanakis G, Schulte C, Kleinbongard P, Heusch G (2015) Across-species transfer of protection by remote ischemic preconditioning with species-specific myocardial signal transduction by reperfusion injury salvage kinase and survival activating factor enhancement pathways. Circ Res 117:279-288. https://doi.org/10.1161/CIRCRESAHA.117.306878

191. Skyschally A, Kleinbongard P, Lieder H, Gedik N, Stoian L, Amanakis G, Elbers E, Heusch G (2018) Humoral transfer and intramyocardial signal transduction of protection by remote ischemic perconditioning in pigs, rats, and mice. Am J Physiol Heart Circ Physiol 315:H159-H172. https://doi.org/10.1152/ ajpheart.00152.2018

192. Sloth AD, Schmidt MR, Munk K, Schmidt M, Pedersen L, Sørensen HT, Bøtker HE, Investigators CONDI (2015) Impact of cardiovascular risk factors and medication use on the efficacy of remote ischaemic conditioning: post hoc subgroup analysis of a randomised controlled trial. BMJ Open 5:e06923. https://doi. org/10.1136/bmjopen-2014-006923

193. Smith CCT, Dixon RA, Wynne AM, Theodorou L, Ong S-G, Subrayan S, Davidson SM, Hausenloy DJ, Yellon DM (2010) Leptin-induced cardioprotection involves JAK/STAT signaling that may be linked to the mitochondrial permeability transition pore. Am J Physiol Heart Circ Physiol 299:H1265-H1270. https://doi.org/10.1152/ajpheart.00092.2010

194. Smith RM, Suleman N, Lacerda L, Opie LH, Akira S, Chien KR, Sack MN (2004) Genetic depletion of cardiac myocyte STAT-3 abolishes classical preconditioning. Cardiovasc Res 63:611-616. https://doi.org/10.1016/j.cardiores.2004.06.019

195. Smith RM, Suleman N, McCarthy J, Sack MN (2002) Classic ischemic but not pharmacologic preconditioning is abrogated following genetic ablation of the TNFalpha gene. Cardiovasc Res 55:553-560. https://doi.org/10.1016/s0008-6363(02)00283-3

196. Sobotta MC, Liou W, Stöcker S, Talwar D, Oehler M, Ruppert T, Scharf AND, Dick TP (2015) Peroxiredoxin-2 and STAT3 form a redox relay for $\mathrm{H} 2 \mathrm{O} 2$ signaling. Nat Chem Biol 11:64-70. https://doi.org/10.1038/nchembio.1695

197. Somers SJ, Frias M, Lacerda L, Opie LH, Lecour S (2012) Interplay between SAFE and RISK pathways in sphingosine1-phosphate-induced cardioprotection. Cardiovasc Drugs Ther 26:227-237. https://doi.org/10.1007/s10557-012-6376-2

198. Song Y, Song JW, Lee S, Jun J-H, Kwak Y-L, Shim J-K (2017) Effects of remote ischemic preconditioning in patients with concentric myocardial hypertrophy: A randomized, controlled trial with molecular insights. Int J Cardiol 249:36-41. https://doi.org/ 10.1016/j.ijcard.2017.08.073

199. Stapel B, Kohlhaas M, Ricke-Hoch M, Haghikia A, Erschow S, Knuuti J, Silvola JMU, Roivainen A, Saraste A, Nickel AG, Saar JA, Sieve I, Pietzsch S, Müller M, Bogeski I, Kappl R, Jauhiainen M, Thackeray JT, Scherr M, Bengel FM, Hagl C, Tudorache I, Bauersachs J, Maack C, Hilfiker-Kleiner D (2017) Low STAT3 expression sensitizes to toxic effects of $\beta$-adrenergic receptor stimulation in peripartum cardiomyopathy. Eur Heart $\mathrm{J}$ 38:349-361. https://doi.org/10.1093/eurheartj/ehw086

200. Strohm C, Barancik M, Brühl M-LV, Kilian SAR, Schaper W (2000) Inhibition of the ER-kinase cascade by PD98059 and UO126 counteracts ischemic preconditioning in pig myocardium. 
J Cardiovasc Pharm 36:218-229. https://doi.org/10.1097/00005 344-200008000-00012

201. Su Y, Huang X, Huang Z, Huang T, Xu Y, Yi C (2020) STAT3 Localizes in mitochondria-associated ER membranes instead of in mitochondria. Front Cell Dev Biol 8:274. https://doi.org/10. 3389/fcell.2020.00274

202. Suleiman M-S, Halestrap AP, Griffiths EJ (2001) Mitochondria: a target for myocardial protection. Pharm Ther 89:29-46. https:// doi.org/10.1016/S0163-7258(00)00102-9

203. Sun X, Chen R, Yang Z, Sun G, Wang M, Ma X, Yang L, Sun X (2014) Taxifolin prevents diabetic cardiomyopathy in vivo and in vitro by inhibition of oxidative stress and cell apoptosis. Food Chem Toxicol 63:221-232. https://doi.org/10.1016/j.fct.2013.11. 013

204. Szczepanek K, Chen Q, Derecka M, Salloum FN, Zhang Q, Szelag M, Cichy J, Kukreja RC, Dulak J, Lesnefsky EJ, Larner AC (2011) Mitochondrial-targeted Signal transducer and activator of transcription 3 (STAT3) protects against ischemia-induced changes in the electron transport chain and the generation of reactive oxygen species. J Biol Chem 286:29610-29620. https:// doi.org/10.1074/jbc.M111.226209

205. Szczepanek K, Chen Q, Larner AC, Lesnefsky EJ (2012) Cytoprotection by the modulation of mitochondrial electron transport chain: the emerging role of mitochondrial STAT3. Mitochondrion 12:180-189. https://doi.org/10.1016/j.mito.2011.08.011

206. Szczepanek K, Xu A, Hu Y, Thompson J, He J, Larner AC, Salloum FN, Chen Q, Lesnefsky EJ (2015) Cardioprotective function of mitochondrial-targeted and transcriptionally inactive STAT3 against ischemia and reperfusion injury. Basic Res Cardiol 110:53. https://doi.org/10.1007/s00395-015-0509-2

207. Takeda K, Noguchi K, Shi W, Tanaka T, Matsumoto M, Yoshida N, Kishimoto T, Akira S (1997) Targeted disruption of the mouse Stat 3 gene leads to early embryonic lethality. Proc Natl Acad Sci U S A 94:3801-3804. https://doi.org/10.1073/pnas.94.8.3801

208. Takeo S, Elmoselhi AB, Goel R, Sentex E, Wang J, Dhalla NS (2000) Attenuation of changes in sarcoplasmic reticular gene expression in cardiac hypertrophy by propranolol and verapamil. Mol Cell Biochem 213:111-118. https://doi.org/10.1023/a:10071 20332587

209. Tamareille S, Mateus V, Ghaboura N, Jeanneteau J, Croué A, Henrion D, Furber A, Prunier F (2011) RISK and SAFE signaling pathway interactions in remote limb ischemic perconditioning in combination with local ischemic postconditioning. Basic Res Cardiol 106:1329-1339. https://doi.org/10.1007/ s00395-011-0210-z

210. Tammineni P, Anugula C, Mohammed F, Anjaneyulu M, Larner AC, Sepuri NBV (2013) The import of the transcription factor STAT3 into mitochondria depends on GRIM-19, a component of the electron transport chain. J Biol Chem 288:4723-4732. https:// doi.org/10.1074/jbc.M112.378984

211. Thibault H, Piot C, Staat P, Bontemps L, Sportouch C, Rioufol G, Cung TT, Bonnefoy E, Angoulvant D, Aupetit J-F, Finet G, André-Fouët X, Macia JC, Raczka F, Rossi R, Itti R, Kirkorian G, Derumeaux G, Ovize M (2008) Long-term benefit of postconditioning. Circulation 117:1037-1044. https://doi.org/10.1161/ CIRCULATIONAHA.107.729780

212. Tullio F, Angotti C, Perrelli MG, Penna C, Pagliaro P (2013) Redox balance and cardioprotection. Basic Res Cardiol 108:392. https://doi.org/10.1007/s00395-013-0392-7

213. Vassalli G, Milano G, Moccetti T (2012) Role of mitogen-activated protein kinases in myocardial ischemia-reperfusion injury during heart transplantation. J Transplant 2012:928954. https:// doi.org/10.1155/2012/928954

214. Vessey DA, Li L, Honbo N, Karliner JS (2009) Sphingosine 1-phosphate is an important endogenous cardioprotectant released by ischemic pre- and postconditioning. Am J Physiol Heart Circ Physiol 297:H1429-H1435. https://doi.org/10.1152/ ajpheart.00358.2009

215. Vinten-Johansen J, Zhao Z-Q, Zatta AJ, Kin H, Halkos ME, Kerendi F (2005) Postconditioning - A new link in nature's armor against myocardial ischemia-reperfusion injury. Basic Res Cardiol 100:295-310. https://doi.org/10.1007/s00395-005-0523-x

216. Vito CD, Hadi LA, Navone SE, Marfia G, Campanella R, Mancuso ME, Riboni L (2016) Platelet-derived sphingosine1-phosphate and inflammation: from basic mechanisms to clinical implications. Platelets 27:393-401. https://doi.org/10.3109/ 09537104.2016.1144179

217. Wang C, Li H, Wang S, Mao X, Yan D, Wong SS, Xia Z, Irwin MG (2018) Repeated non-invasive limb ischemic preconditioning confers cardioprotection through PKC- $\varepsilon$ /STAT3 signaling in diabetic rats. Cell Physiol Biochem 45:2107-2121. https://doi. org/10.1159/000488047

218. Wang K, Li B, Xie Y, Xia N, Li M, Gao G (2020) Statin rosuvastatin inhibits apoptosis of human coronary artery endothelial cells through upregulation of the JAK2/STAT3 signaling pathway. Mol Med Rep 22:2052-2062. https://doi.org/10.3892/mmr. 2020.11266

219. Wang K, Liu Z, Zhao M, Zhang F, Wang K, Feng N, Fu F, Li J, Li J, Liu Y, Zhang S, Fan R, Guo H, Pei J (2020) א-opioid receptor activation promotes mitochondrial fusion and enhances myocardial resistance to ischemia and reperfusion injury via STAT3OPA1 pathway. Eur J Pharmacol 874:172987. https://doi.org/ 10.1016/j.ejphar.2020.172987

220. Wang L-Y, Cheng X-X, Xu Z-L (2020) Regulatory effect of the zinc transporter Zip2 on cardiomyocyte mitochondrial respiration function after cardiac ischemia-reperfusion injury in mice. Sheng Li Xue Bao 72:433-440

221. Wang M, Zhang W, Crisostomo P, Markel T, Meldrum KK, Fu XY, Meldrum DR (2007) Endothelial STAT3 plays a critical role in generalized myocardial proinflammatory and proapoptotic signaling. Am J Physiol Heart Circ Physiol 293:H2101-H2108. https://doi.org/10.1152/ajpheart.00125.2007

222. Wang Y, van Boxel-Dezaire AHH, Cheon H, Yang J, Stark GR (2013) STAT3 activation in response to IL-6 is prolonged by the binding of IL-6 receptor to EGF receptor. Proc Natl Acad Sci U S A 110:16975-16980. https://doi.org/10.1073/pnas.1315862110

223. Wang Y, Levy DE (2012) Comparative evolutionary genomics of the STAT family of transcription factors. JAKSTAT 1:23-33. https://doi.org/10.4161/jkst.19418

224. Waxman AB, Mahboubi K, Knickelbein RG, Mantell LL, Manzo N, Pober JS, Elias JA (2003) Interleukin-11 and interleukin-6 protect cultured human endothelial cells from $\mathrm{H} 2 \mathrm{O} 2$-induced cell death. Am J Respir Cell Mol Biol 29:513-522. https://doi.org/ 10.1165/rcmb.2002-0044OC

225. Wegrzyn J, Potla R, Chwae Y-J, Sepuri NBV, Zhang Q, Koeck T, Derecka M, Szczepanek K, Szelag M, Gornicka A, Moh A, Moghaddas S, Chen Q, Bobbili S, Cichy J, Dulak J, Baker DP, Wolfman A, Stuehr D, Hassan MO, Fu X-Y, Avadhani N, Drake JI, Fawcett P, Lesnefsky EJ, Larner AC (2009) Function of mitochondrial Stat3 in cellular respiration. Science 323:793-797. https://doi.org/10.1126/science.1164551

226. Wever KE, Hooijmans CR, Riksen NP, Sterenborg TB, Sena ES, Ritskes-Hoitinga M, Warlé MC (2015) Determinants of the efficacy of cardiac ischemic preconditioning: a systematic review and meta-analysis of animal studies. PLoS ONE 10:e0142021. https://doi.org/10.1371/journal.pone.0142021

227. Whittaker P, Przyklenk K (2014) From ischemic conditioning to 'hyperconditioning': clinical phenomenon and basic science opportunity. Dose-Response 12:650-663. https://doi.org/10. 2203/dose-response.14-035. Whittaker 
228. Wu J, Guo W, Lin S-Z, Wang Z-J, Kan J-T, Chen S-Y, Zhu Y-Z (2016) Gp130-mediated STAT3 activation by S-propargylcysteine, an endogenous hydrogen sulfide initiator, prevents doxorubicin-induced cardiotoxicity. Cell Death Dis 7:e2339. https://doi.org/10.1038/cddis.2016.209

229. Wu L, Tan J-L, Chen Z-Y, Huang G (2019) Cardioprotection of post-ischemic moderate ROS against ischemia/reperfusion via STAT3-induced the inhibition of MCU opening. Basic Res Cardiol 114:39. https://doi.org/10.1007/s00395-019-0747-9

230. Wu Q, Wang T, Chen S, Zhou Q, Li H, Hu N, Feng Y, Dong N, Yao S, Xia Z (2018) Cardiac protective effects of remote ischaemic preconditioning in children undergoing tetralogy of fallot repair surgery: a randomized controlled trial. Eur Heart J 39:1028-1037. https://doi.org/10.1093/eurheartj/ehx030

231. Xie Y, Kole S, Precht P, Pazin MJ, Bernier M (2009) S-glutathionylation impairs signal transducer and activator of transcription 3 activation and signaling. Endocrinology 150:1122-1131. https:// doi.org/10.1210/en.2008-1241

232. Xu YS, Liang JJ, Wang Y, Zhao X-ZJ, Xu L, Xu Y-Y, Zou QC, Zhang JM, Tu C-E, Cui Y-G, Sun W-H, Huang C, Yang J-H, Chin YE (2016) STAT3 undergoes acetylation-dependent mitochondrial translocation to regulate pyruvate metabolism. Sci Rep 6:39517. https://doi.org/10.1038/srep39517

233. Yang J, Huang J, Dasgupta M, Sears N, Miyagi M, Wang B, Chance MR, Chen X, Du Y, Wang Y, An L, Wang Q, Lu T, Zhang X, Wang Z, Stark GR (2010) Reversible methylation of promoter-bound STAT3 by histone-modifying enzymes. Proc Natl Acad Sci U S A 107:21499-21504. https://doi.org/10.1073/ pnas. 1016147107

234. Yang J, Kunimoto H, Katayama B, Zhao H, Shiromizu T, Wang L, Ozawa T, Tomonaga T, Tsuruta D, Nakajima K (2020) Phospho-Ser727 triggers a multistep inactivation of STAT3 by rapid dissociation of pY705-SH2 through C-terminal tail modulation. Int Immunol 32:73-88. https://doi.org/10.1093/intimm/dxz061

235. Yang R, Lirussi D, Thornton TM, Jelley-Gibbs DM, Diehl SA, Case LK, Madesh M, Taatjes DJ, Teuscher C, Haynes L, Rincón M (2015) Mitochondrial $\mathrm{Ca}^{2+}$ and membrane potential, an alternative pathway for Interleukin 6 to regulate CD4 cell effector function. Elife 4:e06376. https://doi.org/10.7554/eLife.06376

236. Yang R, Rincon M (2016) Mitochondrial Stat3, the Need for Design Thinking. Int J Biol Sci 12:532-544. https://doi.org/10. 7150/ijbs. 15153

237. Yang X-M, Cui L, White J, Kuck J, Ruchko MV, Wilson GL, Alexeyev M, Gillespie MN, Downey JM, Cohen MV (2015) Mitochondrially targeted Endonuclease III has a powerful antiinfarct effect in an in vivo rat model of myocardial ischemia/ reperfusion. Basic Res Cardiol 110:3. https://doi.org/10.1007/ s00395-014-0459-0

238. Yellon DM, Downey JM (2003) Preconditioning the myocardium: from cellular physiology to clinical cardiology. Physiol Rev 83:1113-1151. https://doi.org/10.1152/physrev.00009.2003

239. Yokogami K, Wakisaka S, Avruch J, Reeves SA (2000) Serine phosphorylation and maximal activation of STAT3 during CNTF signaling is mediated by the rapamycin target mTOR. Curr Biol 10:47-50. https://doi.org/10.1016/s0960-9822(99)00268-7

240. Yoon S, Woo SU, Kang JH, Kim K, Kwon M-H, Park S, Shin H-J, Gwak H-S, Chwae Y-J (2010) STAT3 transcriptional factor activated by reactive oxygen species induces IL6 in starvationinduced autophagy of cancer cells. Autophagy 6:1125-1138. https://doi.org/10.4161/auto.6.8.13547

241. Yuan Z-L, Guan Y-J, Chatterjee D, Chin YE (2005) Stat3 dimerization regulated by reversible acetylation of a single lysine residue. Science 307:269-273. https://doi.org/10.1126/science. 1105166
242. Zangrillo A, Musu M, Greco T, Di Prima AL, Matteazzi A, Testa V, Nardelli P, Febres D, Monaco F, Calabrò MG, Ma J, Finco G, Landoni G (2015) Additive Effect on Survival of Anaesthetic Cardiac Protection and Remote Ischemic Preconditioning in Cardiac Surgery: A Bayesian Network Meta-Analysis of Randomized Trials. PLoS ONE 10:e0134264. https://doi.org/10.1371/ journal.pone. 0134264

243. Zhang G, Sheng M, Wang J, Teng T, Sun Y, Yang Q, Xu Z (2018) Zinc improves mitochondrial respiratory function and prevents mitochondrial ROS generation at reperfusion by phosphorylating STAT3 at Ser727. J Mol Cell Cardiol 118:169-182. https://doi. org/10.1016/j.yjmcc.2018.03.019

244. Zhang J, Yang J, Roy SK, Tininini S, Hu J, Bromberg JF, Poli V, Stark GR, Kalvakolanu DV (2003) The cell death regulator GRIM-19 is an inhibitor of signal transducer and activator of transcription 3. Proc Natl Acad Sci U S A 100:9342-9347. https://doi.org/10.1073/pnas.1633516100

245. Zhang L, Zhang J, Liu Y, Zhang P, Nie J, Zhao R, Shi Q, Sun H, Jiao D, Chen Y, Zhao X, Huang Y, Li Y, Zhao J-Y, Xu W, Zhao S-M, Wang C (2021) Mitochondrial STAT5A promotes metabolic remodeling and the Warburg effect by inactivating the pyruvate dehydrogenase complex. Cell Death Dis 12:634. https:// doi.org/10.1038/s41419-021-03908-0

246. Zhang W, Qu X, Chen B, Snyder M, Wang M, Li B, Tang Y, Chen H, Zhu W, Zhan L, Yin N, Li D, Xie L, Liu Y, Zhang JJ, Fu X-Y, Rubart M, Song L-S, Huang X-Y, Shou W (2016) Critical Roles of STAT3 in $\beta$-adrenergic functions in the heart. Circulation 133:48-61. https://doi.org/10.1161/CIRCULATIONAHA. 115.017472

247. Zhao J, Du J, Pan Y, Chen T, Zhao L, Zhu Y, Chen Y, Zheng Y, Liu Y, Sun L, Hang P, Du Z (2019) Activation of cardiac TrkB receptor by its small molecular agonist 7,8-dihydroxyflavone inhibits doxorubicin-induced cardiotoxicity via enhancing mitochondrial oxidative phosphorylation. Free Radic Biol Med 130:557-567. https://doi.org/10.1016/j.freeradbiomed.2018.11. 024

248. Zhao Z-Q, Corvera JS, Halkos ME, Kerendi F, Wang N-P, Guyton RA, Vinten-Johansen J (2003) Inhibition of myocardial injury by ischemic postconditioning during reperfusion: comparison with ischemic preconditioning. Am J Physiol Heart Circ Physiol 285:H579-H588. https://doi.org/10.1152/ajpheart.01064. 2002

249. Zhong Z, Wen Z, Darnell JE (1994) Stat3: a STAT family member activated by tyrosine phosphorylation in response to epidermal growth factor and interleukin-6. Science 264:95-98. https:// doi.org/10.1126/science.8140422

250. Zhu Q, Li H, Xie X, Chen X, Kosuru R, Li S, Lian Q, Cheung CW, Irwin MG, Ge R, Xia Z (2020) Adiponectin facilitates postconditioning cardioprotection through both AMPK-dependent nuclear and AMPK-independent mitochondrial STAT3 activation. Oxid Med Cell Longev 2020:e4253457. https://doi.org/10. $1155 / 2020 / 4253457$

251. Zouein FA, Altara R, Chen Q, Lesnefsky EJ, Kurdi M, Booz GW (2015) Pivotal importance of STAT3 in protecting the heart from acute and chronic stress: new advancement and unresolved issues. Front Cardiovasc Med 30:2-36. https://doi.org/10.3389/ fcvm.2015.00036

252. Zouein FA, Kurdi M, Booz GW (2013) Dancing rhinos in stilettos: The amazing saga of the genomic and nongenomic actions of STAT3 in the heart. JAKSTAT 2:e24352. https://doi.org/10. $4161 /$ jkst. 24352 